\title{
Component Structure of Credit Default Swap Spreads and Their Determinants
}

\author{
Ramaprasad Bhar (Corresponding author) \\ Ph. D., UNSW Business School, UNSW Sydney, Australia \\ E-mail: r.bhar@unsw.edu.au
}

David Colwell

Ph. D., UNSW Business School, UNSW Sydney, Australia

Peipei Wang

Ph. D., Deakin University, Burwood, Victoria 3125, Australia

Received: October 24, 2018 Accepted: November 16, 2018 Published: November 19, 2018

doi:10.5296/ijafr.v8i4.13811

URL: https://doi.org/10.5296/ijafr.v8i4.13811

\begin{abstract}
In this paper, we decompose credit default swap (CDS) spreads into a transitory component and a persistent component and test how these components are affected by the theoretical explanatory variables. We find significant but differing impacts of these explanatory variables on the extracted components. For example, equity volatility seems to have a larger influence on the transitory component, suggesting that its effect may be mostly short-lived, while our proxy for illiquidity has a greater impact on the persistent component indicating its more enduring effect. Also, the slope of the yield curve has impacts with opposite signs on the two components and so our analysis thus helps address the conflicting results reported in earlier studies without such a component framework. These results indicate that a two-factor formulation may be needed to model CDS options.
\end{abstract}

Keywords: Credit default swap, Component structures, Liquidity, Latent factor Models, Kalman filter

\section{Introduction}

A credit derivative is an over-the-counter derivative that is designed to transfer credit risk from one party to another. By dynamically adjusting credit exposures, credit derivatives 
allow institutions to manage credit risk more effectively. Its importance lies not only in risk management activities using Credit Default Swaps (CDS) for hedging purposes, but also for anyone trying to profit from arbitrage possibilities within the CDS market. More incisive research in this market is not only attractive but necessary for better understanding by all participants.

In this paper our data covers the period from June 2004 to May 2007, when the market for credit derivatives was expanding, as well as attracting an increasingly diversified group of users. This is the period leading up to the Global Financial Crisis (GFC) period. Many were attempting to exploit arbitrage opportunities between the credit derivatives market and the underlying bond and stock market, to hedge positions taken in other markets and also for pure speculation or regulatory arbitrage (Bystrom, 2006).

While there are many variations of credit derivatives, the Credit Default Swap (CDS) is among the most intuitive and is commonly cited as a basic "building block" for more complex structures. The owner of a CDS receives a payoff if the underlying financial instrument defaults. Rather than paying for this default insurance in a lump sum, the holder makes periodic payments until the underlying bond either defaults or matures. If one writes these periodic payments as a percentage of the face value per annum, this quantity is known as the CDS spread (or sometimes as the CDS price or CDS rate). The CDS spread behaves much like a credit spread.

In our data, we observe CDS spreads ranging from 20 basis points to 500 basis points, roughly. There are also bid CDS spreads and ask CDS spreads. It is commonly recognized that the credit default swap spread is a comparatively "pure" measure of credit risk (Ericsson et al., 2004). Therefore, a study exploring the determinants and the dynamics of the CDS plays a central role when evaluating credit risk related securities and projects.

The distinguishing features of this paper are as follows. Firstly, we decompose the CDS series of two different maturities into their component structures - a short-term factor and a long-term factor. This is a convenient way to deal with non-stationary time series. The short-term factor is also referred to as the temporary component. Similarly, the long-term component is also referred to as the permanent component. Secondly, we explore the determinants for each of them separately. To the best of our knowledge, such an attempt to analyse CDS spreads via its components has not been reported.

Just to highlight the importance component structures in analysing CDS spreads a simple illustration will help. Consider, for example, the effect of the term structure of interest rates on CDS spreads. In structural models of defaultable debt, the short rate is the firm value's risk-neutral expected growth rate, and so a high short rate implies a lower probability of default. On the other hand, in the long run, high interest rates lead go higher borrowing costs. Indeed, we show that the term structure (its slope in particular) has opposing effects on the short-term and long-term components of the CDS spread. Without these component distinctions the impact of the slope on CDS could turn out to be conflicting, as in Avramov et al. (2007). 


\section{$\triangle$ Macrothink}

International Journal of Accounting and Financial Reporting

ISSN 2162-3082

2018, Vol. 8, No. 4

The next question is how we infer these components given that we only have observations on CDS spreads directly. In this respect we follow the framework of Schwartz and Smith (2000). Using the logarithm of CDS rates, we include two unobserved components in the model in such a way that one component would capture the long-term dynamics and the other would capture the short-term dynamics. The long-term factor is thought to describe the equilibrium spread level (representing a constant fundamental spread level) and is assumed to evolve according to a Brownian motion, with drift reflecting the business cycle, development of the credit derivatives market, as well as political and regulatory effects. The short-term deviations, which are defined as the difference between spot and equilibrium prices, are assumed to follow a mean reverting process. These deviations may reflect, for example, portfolio adjustments or intermittent market disruptions, and temporary credit changes. Since none of these factors is directly observable, we can set up the problem in a state-space framework and use standard Kalman filtering techniques to make optimum inferences about the state variables.

In this paper we focus on several indices of CDS spreads, namely the iTraxx family. Because they are portfolios, the idiosyncratic differences are rendered inconsequential. Thus, we are more concerned with the common factors behind all these CDS spreads. Also, we have chosen three benchmark iTraxx indices, namely iTraxx Europe, iTraxx Europe Hivol and iTraxx Europe Crossover. This allows us to have an overall view of the European CDS market, just by examining these three indices.

Our results show that with the rapid development of the CDS market (or credit derivatives market), the level of CDS spreads is falling during the sample period. This may mainly result from the enhanced efficiency and liquidity of this market. For firms in different credit rating categories, short-term and long-term behaviour is different. The credit default swap spread for underlying entities with higher credit ratings tends to be more volatile in the long term, while the credit default swap spread for underlying entities with lower credit rating tends to be more volatile in the short term.

It is shown that most theoretical explanatory variables, as documented by other researchers, have significant impacts on credit default swap spreads but that they do impact the short-term and long-term dynamic of CDS spreads differently. Moreover, these variables can explain more variations of the long-term dynamic in CDS spreads compared to those of the short-term dynamic.

The remainder of this paper is organised as follows. Section 2 gives the related literature review. Section 3 presents a description of the recent development of the credit derivatives market and the iTraxx index, which is the research objective in this paper. Section 4 provides the data and the methodology. In Section 5 we give the empirical results and explanations of our findings. Section 6 concludes the paper.

\section{Literature Review}

The contemporary literature concentrates on credit spread i.e. the difference in yield on corporate bond and the matching Treasury yield. The focus is on default probabilities and the 
determinants of credit risk. Longstaff and Schwartz (1995a, b) used annual data from 1977 to 1992 in a regression-based analysis of the change in credit spread against the change in the 30-year Treasury rate and the return on an appropriate equity index. Irrespective of maturity, they found the intercept term and coefficients of change of the 30-year Treasury rate increased in absolute magnitude as the credit quality decreased.

Wilson (1997a, b) examined the effects of macro-economic variables, namely GDP growth rate, unemployment rate, long-term interest rate, foreign exchange rate and aggregate savings rate, in estimating the default rate level. Collin-Dufresne, Goldstein and Martin (2001), on the other hand, investigated the determinants of credit spread changes using dealers' quotes and transition prices on industrial bonds. They showed that the proxies for three theoretical determinants, namely default risk, recovery rate upon default, and liquidity, have rather limited explanatory power. Their results suggest that monthly credit spread changes are mainly driven by local supply/demand shocks that are independent of both credit-risk and standard proxies for liquidity.

Studies which directly focus on the determinants of CDS spreads have also been developing rapidly in recent years. Skinner et al. (2003) used arguments from option pricing theory and suggest that the CDS spread should be highly dependent on the risk-free short rate, the yield of the reference obligation, the interest rate volatility, the time to maturity and the recovery rate. They found that four of these variables, (i.e., all except for the recovery rate) contain significant information. Benkert (2004) conducted a regression analysis using CDS panel data, incorporating variables such as credit rating, liquidity, leverage, historical volatility and implied volatility. He found that implied volatility has a stronger effect than historical volatility, and that both remain relevant in the presence of credit ratings which contribute an equal amount of explanatory power. Ericsson et al. (2005) and Abid and Naifar (2006a) and (2006b), argued for the importance of several explanatory variables to determine the market-wide movements of CDS spreads, while Avramov et al. (2007) did similar work with credit spreads.

The component separation approach taken in this paper leads to deeper understanding of the effect of other economic variables on CDS spread. The interpretation of long-term and short-term factors in Schwartz and Smith (2000) is in line with our persistent and temporary components, respectively. Zhou and Qing (2000) also take a similar approach, working with logarithmic stock prices.

\section{Credit Derivatives Market and iTraxx Indices}

The structured credit derivatives market encompasses a wide range of capital market products designed to transfer credit risk among investors through over-the-counter transactions. Credit Default Swap (CDS) spreads among the most intuitive. From Table 1, obtained from the British Bankers' Association 2006 Credit Derivatives Report, single-name credit default swaps still represented a substantial section of the market, although their share had fallen to $33 \%$. During the same time period, the share of full index trades had increased to $30 \%$ as of the first quarter of 2006 and became the second largest section of the credit derivatives 


\section{Mll Macrothink}

International Journal of Accounting and Financial Reporting

ISSN 2162-3082

2018, Vol. 8, No. 4

market. Figure 1 plots the global market size of credit derivatives from 1996 to 2008 (estimated).

In a manner like the way a stock index is created, a CDS index, for example the iTraxx index, is a portfolio of single-name credit default swaps which should diversify any diversifiable risk. The iTraxx index family consists of various indices of the most liquid CDS contracts in Europe and Asia (in the US, since April 2004, a similar family of indices is called the Dow Jones CDX).

Table 1. BBA credit derivatives panel

\begin{tabular}{lllll}
\hline Type & 2000 & 2002 & 2004 & 2006 \\
\hline Basket products & $6.0 \%$ & $6.0 \%$ & $4.0 \%$ & $1.8 \%$ \\
\hline Credit linked notes & $10.0 \%$ & $8.0 \%$ & $6.0 \%$ & $3.1 \%$ \\
\hline Credit spread options & $5.0 \%$ & $5.0 \%$ & $2.0 \%$ & $1.3 \%$ \\
\hline Equity linked credit products & $\mathrm{n} / \mathrm{a}$ & $\mathrm{n} / \mathrm{a}$ & $1.0 \%$ & $0.4 \%$ \\
\hline Full index trades & $\mathrm{n} / \mathrm{a}$ & $\mathrm{n} / \mathrm{a}$ & $9.0 \%$ & $30.1 \%$ \\
\hline Single-name credit default swaps & $38.0 \%$ & $45.0 \%$ & $51.0 \%$ & $32.9 \%$ \\
\hline Swaptions & $\mathrm{n} / \mathrm{a}$ & $\mathrm{n} / \mathrm{a}$ & $1.0 \%$ & $0.8 \%$ \\
\hline Synthetic CDOs - full capital & $\mathrm{n} / \mathrm{a}$ & $\mathrm{n} / \mathrm{a}$ & $6.0 \%$ & $3.7 \%$ \\
\hline Synthetic CDOs - partial capital & $\mathrm{n} / \mathrm{a}$ & $\mathrm{n} / \mathrm{a}$ & $10.0 \%$ & $12.6 \%$ \\
\hline Trenched index trades & $\mathrm{n} / \mathrm{a}$ & $\mathrm{n} / \mathrm{a}$ & $2.0 \%$ & $7.6 \%$ \\
\hline Others & $41.0 \%$ & $36.0 \%$ & $8.0 \%$ & $5.7 \%$ \\
\hline
\end{tabular}

Note: The table reports the market proportion of different credit derivatives product, which is taken from the British Banker's Association (BBA) 2006 Credit Derivatives Report.

The benchmark iTraxx Europe index comprises 125 equally-weighted investment grade European names which are selected by a dealer poll based on CDS volume traded over the previous six months. Other than the benchmark iTraxx Europe index, there are two other popular benchmark iTraxx indices. These are the benchmark iTraxx Europe Crossover index, comprising the 25-50 sub-investment grade entities from iTraxx Europe and the benchmark 


\section{Mll Macrothink}

International Journal of Accounting and Financial Reporting

ISSN 2162-3082

2018, Vol. 8, No. 4

iTraxx Europe Hivol index, consisting of the 30 names with the widest CDS spreads from iTraxx Europe.

The iTraxx indices typically trade 5 and 10-year maturities and a new series is determined by a dealer liquidity poll every 6 months. The Europe and Hivol indices also trade 3 and 7-year maturities. The indices are managed and administered by the International Index Company, which is owned by a group of the largest global investment banks. All index quotes for our study have been made available by the International Index Company.

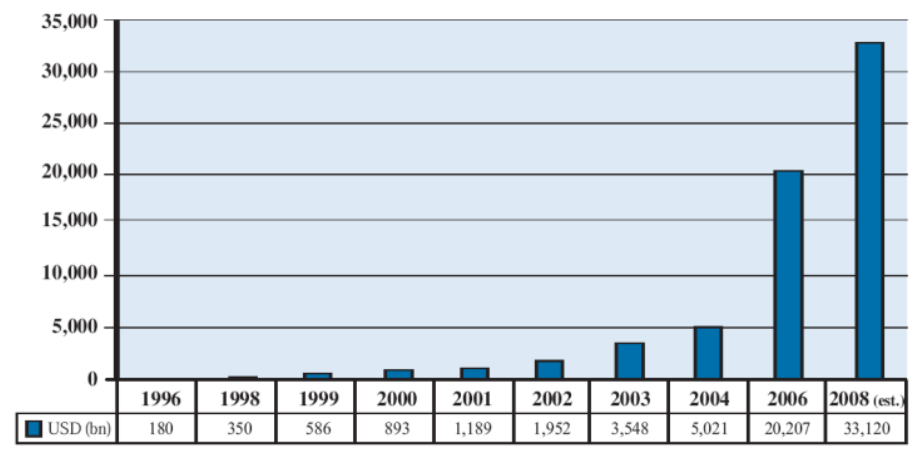

Figure 1. Global credit derivatives market \$billion

Source: British Bankers' Association, Credit Derivatives Report 2006

\section{Data and Methodology}

This section provides a detailed description of the data and methodology adopted in this paper. These include the iTraxx indices, the theoretical explanatory variables of credit default spreads, and the state-space model for extracting the components.

\subsection{Data}

This paper examines the natural logarithm of the CDS index represented by three benchmark iTraxx indices. The theoretical explanatory variables considered in this paper are: the short interest rate, the slope of yield curve, the stock market volatility, the bid-ask spread for each iTraxx index, and each maturity and credit rating premia. The data consists of daily time series (749 observations), covering the period June 21, 2004 to May 29, 2007. The iTraxx indices and the level of the interest rates are expressed in basis points, annually. All computations are carried out with the natural logarithm of these variables to be consistent.

\section{2 iTraxx Index Characteristics}

The three benchmark iTraxx indices used in this study are iTraxx Europe, iTraxx Europe Hivol and iTraxx Europe Crossover. These three benchmark iTraxx indices give us a complete overview of the whole European CDS market. All these indices are traded with 5 -year as well as 10-year maturity and are denominated in Euro.

The iTraxx Europe index is made up of 125 equally weighted investment grade European names, and is used as a benchmark index. These 125 component names are updated every six months by a dealer poll based on CDS volume traded over the previous six months. 


\section{MInstitute Macrothink $_{\text {Int }}$}

International Journal of Accounting and Financial Reporting

ISSN 2162-3082

2018, Vol. 8, No. 4

Appendices A, B and C list the component names for each of three benchmark iTraxx indices in series 7, which is an iTraxx index time series covering the period from September 20, 2006 to March 19, 2007.

Figure 2 plots these iTraxx indices along the time axes and gives readers a rough idea of the dynamic behaviour of the CDS index. Table 2 gives descriptive statistics for both (the natural logarithm of) the iTraxx index level and its first difference. For example, in logarithmic form, index levels range from 3.0143 to 6.2222, which correspond to CDS spreads of exp (3.0143) $=20.4$ basis points to $\exp (6.2222)=503.8$ basis points .

There are several points we would like to emphasise, based on Figure 2. Firstly, it is not surprising that the iTraxx index level is monotonically increasing with maturity, which is consistent with the upward slope of the term structure of CDS spreads.

Secondly, we notice that there is a less obvious downward trend in our sample period, which is quite different from recent credit derivatives markets which suffered from the collapse of the U.S. subprime market. Also, the obvious downward trend in the first nine months of the sample period preceded the problems faced by General Motors (GM) and Ford. Ford and General Motors are two of the world's biggest car companies, as recorded by the web site www.financialpolicy.org. GM had $\$ 290$ billion in outstanding debt and Ford had another $\$ 160$ billion, for a total of $\$ 450$ billion. Given the massive size of the auto makers' debt, this turbulence seems to have spread across the Atlantic to the European auto sector and thus affected the whole iTraxx. For example, the iTraxx Autos 5Y was up 16.45 basis points from 65.66 basis points on 5 May, 2005 to 82.11 basis points on 18 May, 2005; while iTraxx Europe $5 \mathrm{Y}$ rose from 42.56 basis points to 57.89 basis points during the same period. Despite this turbulence in the credit derivatives market, the overall downward trend in iTraxx indices during our sample period is observable in our estimation results.

Thirdly, it is interesting to note that the spreads between the 5-year maturity and the 10-year maturity are wider with the passing of time, which may be because the 5-year contract became more actively traded than the 10-year maturity with the development of the CDS market. It also may be the impact of the leverage ratio. The mean-reversion feature [Collin-Dufresne and Goldstein (2001)] in the leverage ratio can significantly increase the credit spreads of long-term debt but has little impact on the short-term credit spreads, since the change in the default boundary in the short term is negligible.

Table 2. Descriptive statistics for iTraxx index level and spread changes

iTraxx Europe

iTraxx Europe HiVol iTraxx Europe Crossover

\begin{tabular}{lllllll}
\hline Maturity & $5 \mathrm{Y}$ & $10 \mathrm{Y}$ & $5 \mathrm{Y}$ & $10 \mathrm{Y}$ & $5 \mathrm{Y}$ & $10 \mathrm{Y}$ \\
\hline
\end{tabular}

Panel A: Descriptive Statistics for natural logarithm of iTraxx index level

$\begin{array}{lllllll}\text { Min } & 3.0143 & 3.6936 & 3.6784 & 4.2356 & 5.0102 & 5.2941\end{array}$




\begin{tabular}{lcccccc}
\hline Mean & 3.4898 & 3.9642 & 4.1005 & 4.5124 & 5.5451 & 5.7771 \\
\hline Median & 3.5660 & 3.9886 & 4.1143 & 4.4906 & 5.5848 & 5.7977 \\
\hline Max & 4.0962 & 4.4145 & 4.7465 & 4.9978 & 6.0970 & 6.2222 \\
\hline Stdev & 0.2090 & 0.1329 & 0.2081 & 0.1429 & 0.1686 & 0.1320 \\
\hline Skewness & -0.3613 & -0.1273 & 0.0229 & 0.4388 & -0.4760 & -0.8286 \\
\hline Kurtosis & -0.5593 & -0.4042 & -0.7839 & -0.5470 & 0.5606 & 1.9650 \\
\hline ADF Test & 0.6900 & 0.4700 & 0.4700 & 0.2700 & 0.1600 & 0.0900 \\
\hline PP test & 0.7000 & 0.5500 & 0.5100 & 0.3500 & 0.1900 & 0.1200 \\
\hline
\end{tabular}

Panel B: Descriptive Statistics for the first difference of natural logarithm of iTraxx index level

\begin{tabular}{lllllll}
\hline Min*100 & -11.1463 & -8.7046 & -11.6056 & -9.7667 & -9.3260 & -7.8149 \\
\hline Mean*100 & -0.1029 & -0.0451 & -0.0870 & -0.0280 & -0.0601 & -0.0077 \\
\hline Median*100 & -0.1344 & -0.1115 & -0.2500 & -0.1471 & -0.2317 & -0.1669 \\
\hline Max*100 & 19.3867 & 12.8844 & 22.7082 & 16.3525 & 32.1692 & 26.8990 \\
\hline Stdev & 0.0199 & 0.0143 & 0.0230 & 0.0183 & 0.0257 & 0.0203 \\
\hline Skewness & 1.43822 & 0.9745 & 2.3215 & 2.1637 & 4.0378 & 4.2130 \\
\hline Kurtosis & 16.3768 & 12.4792 & 21.1226 & 22.3978 & 40.3180 & 46.9672 \\
\hline ADF Test & 0.0000 & 0.0000 & 0.0000 & 0.0000 & 0.0000 & 0.0000 \\
\hline PP test & 0.0000 & 0.0000 & 0.0000 & 0.0000 & 0.0000 & 0.0000 \\
\hline
\end{tabular}

Panel C: Descriptive Statistics for log return on MSCI

\begin{tabular}{lllllll} 
Min*100 & Mean*100 & Median*100 & Max*100 & Stdev & Skewness & Kurtosis \\
\hline-3.1640 & 0.0806 & 0.1110 & 2.5108 & 0.0076 & -0.4333 & 1.6111 \\
\hline
\end{tabular}




\section{Mll Macrothink}

International Journal of Accounting and Financial Reporting

ISSN 2162-3082

2018, Vol. 8, No. 4

Note: 1. Panel A provides descriptive statistics for natural logarithm of the level of each iTraxx Europe Index used in this paper and they are iTraxx Europe 5Y, iTraxx Europe 10Y, iTraxx Europe Hivol 5Y, iTraxx Europe Hivol 10Y, iTraxx Europe Crossover 5Y and iTraxx Europe Crossover 10Y.

2. Panel B provides descriptive statistics for the log-return, that is calculated as the first difference of natural logarithm of index level for each of these 6 iTraxx Europe Index; Panel $\mathrm{C}$ provides descriptive statistics of log return on MSCI Europe index.

3. MacKinnon approximate p-value is listed in row of Augmented Dickey-Fuller test (ADF Test) and Phillips-Perron test (PP Test) with unit root test model without trend and with 4 lags.

Fourthly, turning to Table 2, to the extent that the spread is a compensation for credit risk, it is not surprising that the sub-investment grade firms are considered riskier by the market. Accordingly, the iTraxx Europe Crossover index gives the widest CDS index spread in the sample period, which is consistent with theoretical and empirical findings that credit rating is the main determinant of the credit default swap spread. For example, the average credit rating for iTraxx Europe is A2/A2, while it is Ba3/B1 for iTraxx Europe Crossover. The standard deviations for each spread are quite close to each other, with a standard deviation of about $219 \%$ on an annual basis, and this deviation is much higher than that of a stock index.

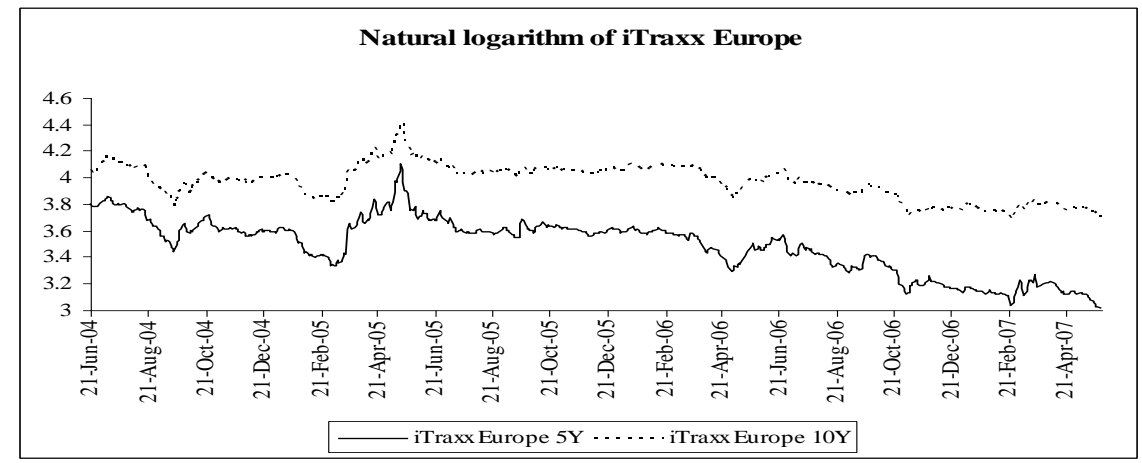

Panel A. iTraxx Europe

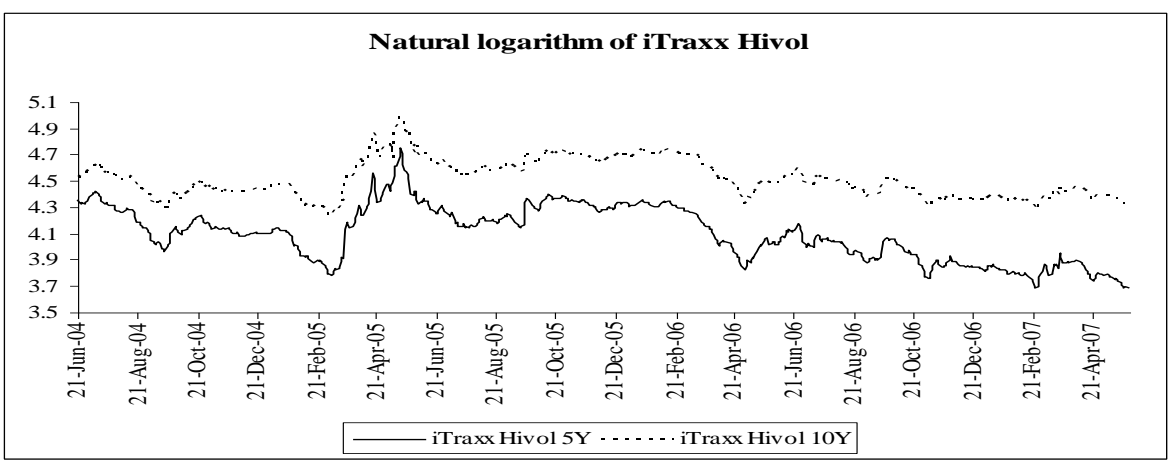

Panel B. iTraxx Europe Hivol 


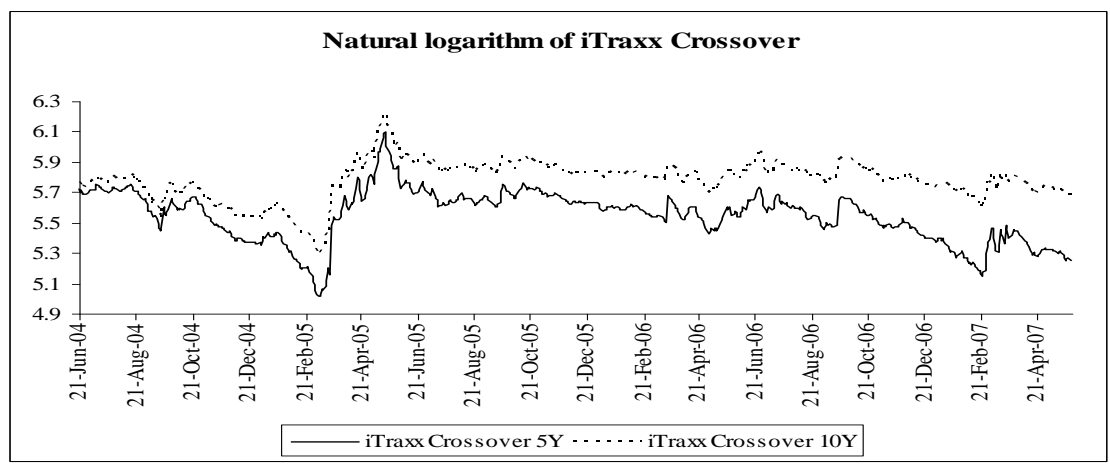

Panel C. iTraxx Europe Crossover

Figure 2. Three benchmark iTraxx Europe indices

When it comes to the distribution of daily log differences on iTraxx index and stock index, we find that the distribution for a CDS index is much more skewed and leptokurtic than that of $\log$ differences on a stock index. This log difference on the iTraxx index is also at least two to three times more volatile than stock index return. The volatilities for CDS spreads range from $23.8 \%$ to $42.7 \%$ on an annual basis, while in the case of the stock index the volatility is around $12.6 \%$ on an annual basis. All these observations tend to indicate that the CDS market is reacting relatively more strongly to credit deteriorations than to credit improvements, in comparison to the stock market. With reference to the three iTraxx indices, the iTraxx Europe Crossover index has especially significant large positive skewness and kurtosis. This may indicate that the CDSs with a lower previous grade react relatively more strongly to credit deteriorations than to credit improvements, as suggested by Norden \& Weber (2004).

In order to adopt the framework of Schwartz and Smith (2000) to decompose the time series of the iTraxx index, we need to confirm the non-stationarity of the original iTraxx indices. It then allows us to separate the two components, that is the short-term and the long-term dynamics. We, thus, perform both the Augmented Dickey-Fuller test and the Phillips-Perron test for these series. For robustness, we try different model specifications and different lags. The results are quite similar, and for simplicity, here we just list the results for the unit root test without trend and with four lags. The Unit Root test shows that all iTraxx indices are non-stationary at the 5\% significance level while all daily log-difference on iTraxx indices are stationary.

\subsection{Discussion on Explanatory Variables}

Published literature, for example Ericsson et al. (2005) and Abid and Naifar (2006a) and (2006b), have argued for the importance of several explanatory variables to explain the market-wide movements of CDS spreads. In this paper we also use those variables to analyse the components of CDS spreads. Specifically, the explanatory variables in this paper include credit ratings, the short-term interest rate, the slope of the yield curve, equity volatility and some measure of liquidity. 


\subsubsection{Credit Rating}

The premium related to credit rating is a very important determinant of credit-related securities including CDSs. We use the difference between the iTraxx Europe Crossover index level and the iTraxx Europe index level to proxy the credit rating premia effect. When credit rating premia become larger, a protection seller will charge more for a lower credit rating underlying entity all else being equal. We would expect credit rating premia to be more closely related to the transitory component because from an equilibrium point of view, the credit rating premia should keep flat, although they will fluctuate over time. It is also conceivable that the credit default swap spreads of the underlying entity with a lower credit rating are more sensitive to information in the short term. Therefore, we would expect to see that the transitory component, especially the transitory component from iTraxx Crossover, to be more sensitive to this variable.

Agencies like Moody's and S\&P provide credit ratings for sovereign and corporate bond issues. Ratings above or on Baa3 (Moody's) and BBB- (S\&P) are referred to as investment grade. Since there is no credit rating assigned to the iTraxx index directly, the rating of iTraxx index in this paper is calculated as the average of the ratings of its component companies. Although each new series of iTraxx index is determined every six months and the entity name incorporated in each index may change over different series, the change in average credit ratings is thought to be trivial. So, we calculate the average credit rating based on the iTraxx Europe Series 7 membership list which can be found on the website of the International Index Company. The ratings assessed for each issuer by Moody's and S\&P are quite similar, and we adopt the rating of Moody's if there is a rating provided; otherwise, we adopt the rating of S\&P. We use a numerical equivalent of the credit rating exhibited in Table 3. In Appendices $\mathrm{A}, \mathrm{B}$ and $\mathrm{C}$ we provide the average credit rating for each of our three benchmark iTraxx indices. It is not surprising that the iTraxx Europe Crossover has the lowest credit rating, with average Ba3/B1, while the iTraxx Europe has the highest credit rating, corresponding to the lowest CDS spread. The average credit rating of each index does not change much over time, and so is not a useful proxy for credit rating premia, but the spread between the index with the highest credit rating and the index with the lowest credit rating is a useful proxy, as we now discuss.

Figure 3 plots the credit rating premia for both 5-year maturity indices and 10-year maturity indices, which is calculated as the logarithm of the level of the iTraxx Europe Crossover index minus the logarithm of the level of the corresponding iTraxx Europe index. The two curves are almost parallel, which on the one hand confirms that the credit rating is a key determinant of a credit default swap spread as well as time to maturity. On the other hand, it shows that the proxy for our credit rating premia is quite reasonable.

Table 3. Numerical value of credit rating

\begin{tabular}{lll}
\hline Moody's & S\&P & Numerical Value \\
\hline Aaa & AAA & 1 \\
\hline
\end{tabular}




\begin{tabular}{lll} 
Aa1 & AAt & 2 \\
\hline Aa2 & AA & 3 \\
\hline Aa3 & AA- & 4 \\
A1 & A+ & 5 \\
\hline A2 & A & 6 \\
\hline A3 & A- & 7 \\
\hline Baa1 & BBB+ & 8 \\
\hline Baa2 & BBB & 9 \\
\hline Baa3 & BBB- & 10 \\
\hline Ba1 & BB+ & 11 \\
\hline Ba2 & BB & 12 \\
Ba3 & BB- & 13 \\
B1 & B+ & 14 \\
\hline B2 & B & 15 \\
\hline B3 & B- & 16 \\
\hline Caa1 & CCC+ & 17 \\
\hline Caa2 & CCC & 18 \\
Caa3 & CCC- & 19 \\
\hline
\end{tabular}

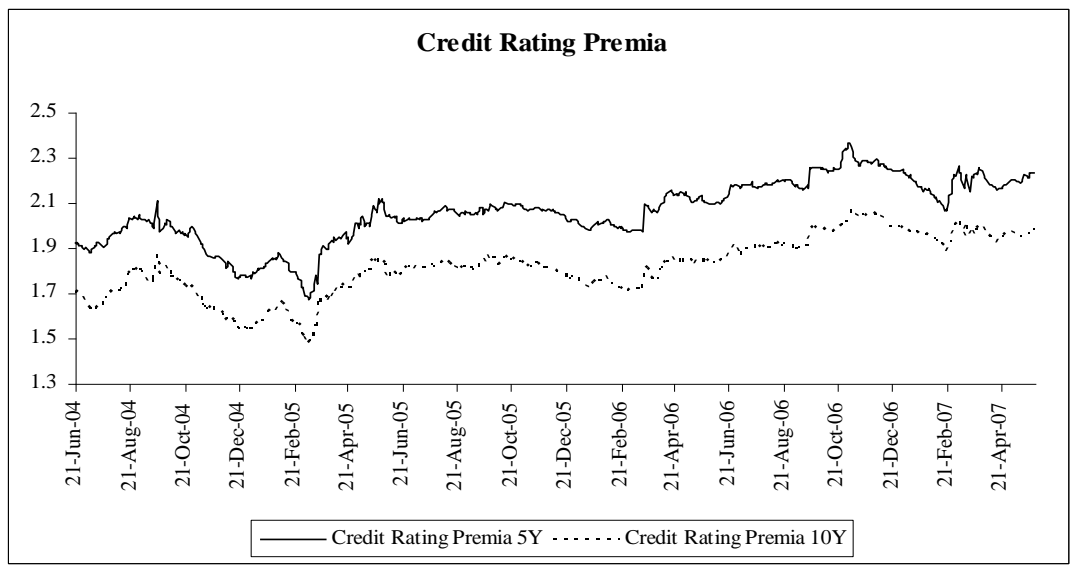

Figure 3. Three credit rating premia for two different maturities

Credit Rating Premia 5Y is defined as natural logarithm of Markit iTraxx Crossover 5Y minus natural logarithm of Markit iTraxx Europe 5Y; Credit Rating Premia 10Y is defined as Markit iTraxx Crossover 10Y minus Markit iTraxx Europe 10Y. All Markit iTraxx indices are taken basis points. 


\section{MlMacrothink}

International Journal of Accounting and Financial Reporting

ISSN 2162-3082

2018, Vol. 8, No. 4

\subsubsection{Short-Term Interest Rate}

It is widely argued that credit risk cannot be priced independently from market risk, especially interest rate risk [Jarrow and Yildirim (2002)]. For example, Duffie and Singleton (1999) assume that the intensity of default in reduced form models is a stochastic process that derives its randomness from a set of variables such as the short-term interest rate. Several choices can be made for the short-term interest rate proxy. For example, Ait-Sahalia (1996a, b) used 7-day Eurodollar rates and Stanton (1997) used 3-month Treasury bill rates. Taking into consideration market region and data accessibility, we use the 3-month Euribor rate as the proxy for the short-term interest rate. We obtained this data from Datastream. Daily observations are used, and we apply the 3-month Euribor rate for the day prior to the credit default swap quote. Figure 4 plots these 3-month Euribor rates covering our sample period.

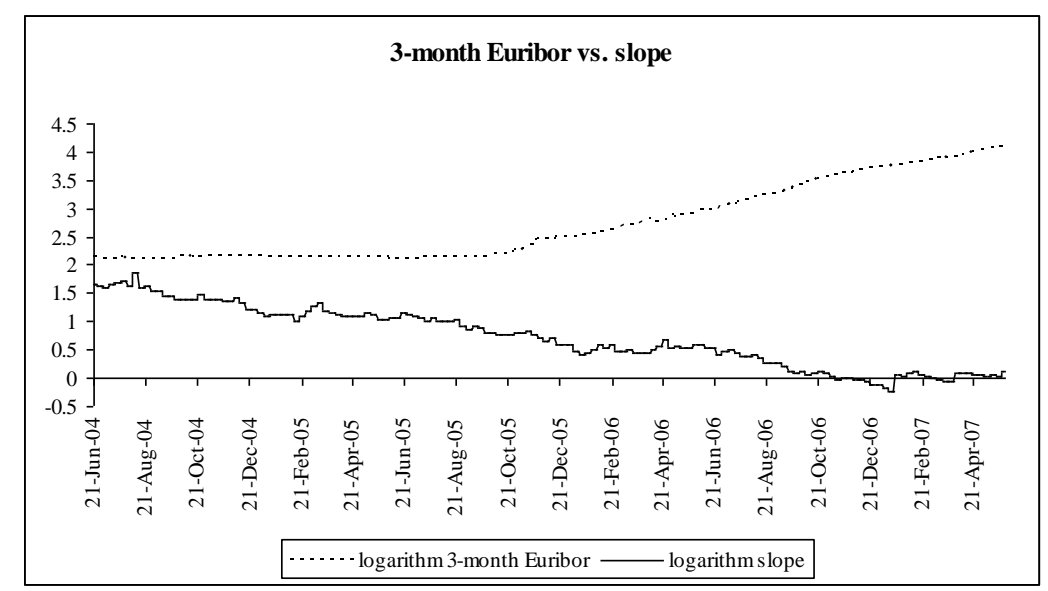

Figure 4. 3-Months Euribor and slope of yield curve

A negative relationship between the level of the short-term interest rate and the credit spread has been documented for several datasets; see for example Longstaff and Schwartz (1995 a, b) or Duffee (1998). Similarly, Abid and Naifar (2005) find the use of the risk-free interest rate as an explanatory variable increases the total adjusted $R^{2}$ and the variable risk-free interest rate is negatively correlated to the levels of credit default swap spreads. That is, an increase in the short-term interest rate leads to a reduction in the spreads. This can be easily explained within a structure model framework. In a structure model, the risk-neutral distribution of an entity's future value depends on the risk-free rate $r$. If $r$ is high, the expected value of the future firm value should also be higher, and therefore, the default probability should be lower under the risk-neutral probability measure, implying a lower CDS [Zhou (2001)].

Moreover, when we examine its influence on both the transitory component and the persistent component, it is reasonable to hypothesise that the short-term interest rate will have more influence on the transitory component than on the persistent component, while for example, the long-term rate should have more influence on the persistent component. We do not use the long-term rate in our regressions, but we do use the slope of the yield curve, which has a slightly more complicated impact on CDS rates, as we discuss below. 


\subsubsection{Slope of the Yield Curve}

The slope of yield curve, which can be interpreted as an indication of overall economic health, has the following predicted impact on CDS spreads. It is measured as the difference between the long-term interest rate and the short-term interest rate. We use the European 10-year government bond yield minus the European 2-year government bond yield. All these daily data are downloaded from Datastream, and as with the short-term interest rate, we take the data for the day prior to the credit default swap quote and plot it in Figure 4. It demonstrates two different patterns in the short-term interest rate and the slope of yield curve. For the short-term interest rate, it is flat during the first 16 months of our sample period, and then continuously increases during the rest of the period, while the slope of yield curve goes the other way, decreasing with time passing. This decrease in the slope mainly results from the increasing short-term interest rate.

Collin-Dufresne, Goldstein and Martin (2001) report conflicting findings regarding the relationship between the slope of the term structure and the credit spread. They conclude that the slope, calculated as the 10-year interest rate minus the 2-year interest rate, is not a significant explanatory variable, either statistically or economically. This is in line with the results of Ericsson et al. (2005) based on credit default swap spreads. However, Abid and Naifar (2005) find a significant negative relationship between credit default swap spreads and the slope of the yield curve. Meanwhile, Avramov et al. (2007) find the slope calculated as the 30-year interest rate minus the 2-year interest rate to be significantly positively related, and the slope calculated as 5-year interest rate minus 2-year interest rate to be significantly negatively related with changes in credit spreads based on constant maturity yield curves. Since the studies do not use a component structure, these conflicting empirical results possibly come from the mixed influence of the temporary and persistent components. We argue that our approach in this paper, based on component structures, may reconcile some of these conflicting observations.

Theoretically, an increase in the slope of the yield curve should increase the expected future short-term interest rate, resulting in a decrease in CDS spreads if the negative relationship between credit risk and the short-term interest rate holds. On the other hand, a positive slope may also signal a higher long-term borrowing cost, which in the short term may not impact on punctual commitment, represented by the principal and interest payments owed to a debt holder, while in the long term may increase the probability of default. So, in our later analysis, we would expect to see a different influence of the slope of yield curve on the temporary component and the persistent component.

\subsubsection{Volatility of Equity}

The volatility of equity is the main driver of credit risk in structural models. Abid and Naifar (2006a) finds that the equity return volatility of reference entities can be a proxy for default risk. The volatility they use is estimated from a GARCH $(1,1)$ model. It is now commonplace to measure volatility in financial time series using GARCH models. These models are based on the notion that the innovations of a time series unconditionally have a fixed variance, but 


\section{Mll Macrothink}

International Journal of Accounting and Financial Reporting

ISSN 2162-3082

2018, Vol. 8, No. 4

that volatility clustering occurs in the sense that the conditional variance of the process varies over time. The GARCH $(1,1)$ can be expressed as following:

$$
h_{t}=\alpha_{0}+\alpha_{1} \varepsilon_{t-1}^{2}+\alpha_{3} h_{t-1}
$$

where $\varepsilon_{t}$ is the innovation in the levels and $h_{t}$ is the conditional variance on date $t$.

We adopt the Morgan Stanley Capital International (MSCI) Europe Index (obtained from DataStream) as the representation of the aggregate European equity market. The MSCI Europe Index is a free float-adjusted market capitalisation index that is designed to measure developed market equity performance in Europe. As of August 2007, the MSCI Europe Index consisted of the following 16 developed country market indices: Austria, Belgium, Denmark, Finland, France, Germany, Greece, Ireland, Italy, the Netherlands, Norway, Portugal, Spain, Sweden, Switzerland, and the United Kingdom.

To estimate time-varying volatility from a $\operatorname{GARCH}(1,1)$ model, we also need to choose a mean equation. We assume the following return specification to generate time-varying volatility estimates of the equity market as a whole:

$$
r_{t}=c+\varepsilon_{t}
$$

This constant $c$ is the mean of the series and $\varepsilon_{t}$ is the residual or the difference between the realised value and the mean. If there is autocorrelation and partial autocorrelation in these squared residual series $\varepsilon_{t}^{2}$, it is a signal that the variance is a predictable process. The statistic to be used here to test for autocorrelation and partial autocorrelation is the Ljung-Box Q-Statistic. Our Q-Statistic value is quite large, which suggests the existence of autocorrelation and partial autocorrelation. When we regress $\varepsilon_{t}^{2}$ on its $k$ lagged values, the results suggest the presence of an ARCH effect. Thus, it is very reasonable for us to use a GARCH $(1,1)$ model to estimate time-varying volatility.

To obtain robust results, we test several other time series dynamics (ARMA) for the mean of the equity return data, as well as different lag specifications for the GARCH variance part. Using the Akaike (AIC) and the Bayesian (BIC) information criteria we compare the alternative models. We finally choose a model that is as simple as possible, given their comparable performance and focus on the constant mean and GARCH $(1,1)$ version. Intuitively, we expect this equity market volatility to be more related to the temporary component. Figure 5 plots the estimated time-varying volatility over our sample period. 


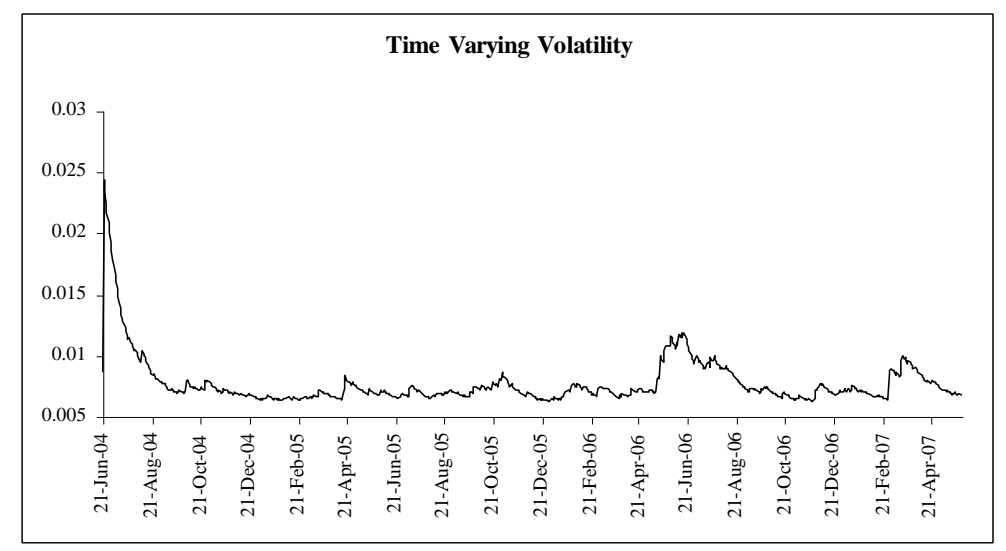

Figure 5. European equity market volatility $(\operatorname{GARCH}(1,1)$ type)

\subsubsection{Bid-Ask Spread (Proxy for Liquidity)}

We use the bid-ask spread as a proxy variable for the illiquidity factor. It has been widely suggested that financial securities subject to default risk also contain a premium for bearing illiquidity risk; see for example Driessen (2005) for liquidity factors in credit spreads, or Longstaff et al. (2005) for liquidity factors in credit default swaps. Theoretically, assets with more liquidity have a lower credit spread. A higher bid-ask spread means low liquidity, which would lead to a higher CDS spread.

For the illiquidity proxy used in this paper we calculate the ask quote minus the bid quote and then take its natural logarithm for each iTraxx index with 5-year maturity as well as 10-year maturity. We plot these illiquidity proxies in Figure 6. Usually, bid-ask spreads of 10-year maturity contracts are higher than those of 5-year maturity contracts for the same iTraxx series. Among all these iTraxx indices, iTraxx Europe Crossover has the highest bid-ask spread because of its sub-investment grade components. In our analysis, we would expect to find that the illiquidity proxy is positively correlated with the iTraxx index level, especially with the transitory component in our paper.

\subsection{Methodology}

\subsubsection{Latent Two-Component Model for iTraxx Indices}

Our previous Unit root test shows that all iTraxx indices of interest are non-stationary at the 5\% significant level. Like Schwartz and Smith (2000) and Zhou and Qing (2000), we describe the natural logarithm of each iTraxx index as a linear combination of a temporary component and a persistent component. The temporary component is assumed to be stationary and the persistent component is represented by a non-stationary dynamic. Our model for the dynamic behaviour of the natural logarithm of CDS spreads for two different maturities is as follows:

$$
\begin{gathered}
{\left[\begin{array}{c}
C D S_{t}^{5} \\
C D S_{t}^{10}
\end{array}\right]=\left[\begin{array}{l}
a \\
b
\end{array}\right]+\left[\begin{array}{ll}
1 & 1 \\
1 & d
\end{array}\right]\left[\begin{array}{l}
X_{1, t} \\
X_{2, t}
\end{array}\right]+\left[\begin{array}{c}
\varepsilon_{1, t} \\
\varepsilon_{2, t}
\end{array}\right]} \\
d X_{1}=-k X_{1} d t+\sigma_{1} d W_{1}
\end{gathered}
$$




$$
d X_{2}=\mu d t+\sigma_{2} d W_{2}
$$

where

$\operatorname{CDS}_{t}^{T}$ is the natural logarithm of the CDS rate at time $t$ with constant maturity $T$;

$X_{1}$ is the temporary and $X_{2}$ is the persistent component of $C D S_{t}$ respectively;

$d$ is the parameter of the persistent component in the $C D S_{t}^{10}$ equation;

$\varepsilon_{i, t}$ is the error term, which is assumed to have an independent identical distribution with mean 0 and variance $\sigma_{\varepsilon, i}^{2} \quad i=1,2$;

The temporary component $X_{1}$ follows an Ornstein-Uhlenbeck process which is also known as a mean-reverting stochastic process. It is generally given by the following stochastic differential equation, where $\theta$ is the level to which $X_{1, t}$ reverts:

$$
d X_{1, t}=k\left(\theta-X_{1, t}\right) d t+\sigma_{1} d W_{1, t}
$$

Setting $\theta$ in our case equal to 0 and integrating equation (6) within interval $[0, t]$ we get

$$
X_{1, t}=X_{1,0} e^{-k t}+\sigma_{1} \int_{0}^{t} e^{-k(t-s)} d W_{1, s}
$$

As a consequence, the temporary component $X_{1}$ is normally distributed with mean and variance given by

$$
\begin{gathered}
E\left\{X_{1, t}\right\}=X_{1,0} e^{-k t} \\
\operatorname{Var}\left\{X_{1, t}\right\}=\frac{\sigma_{1}^{2}}{2 k}\left[1-e^{-2 k t}\right]
\end{gathered}
$$

Notice, indeed, that the drift of the process $X_{1}$ is positive whenever $X_{1}$ is below $\theta$ (which equals 0 here) and negative otherwise, so that at any time $X_{1}$ tends to be pushed 
towards the level $\theta(=0)$. Also, $\theta(=0)$ can be regarded as a long-term average level of $X_{1}$.

Here, $k$ and $\sigma_{1}$ are constants and are positive. Note that this approach is related to the Hull and White (1994) two-factor model, although one of the factors has no mean reversion in our case.

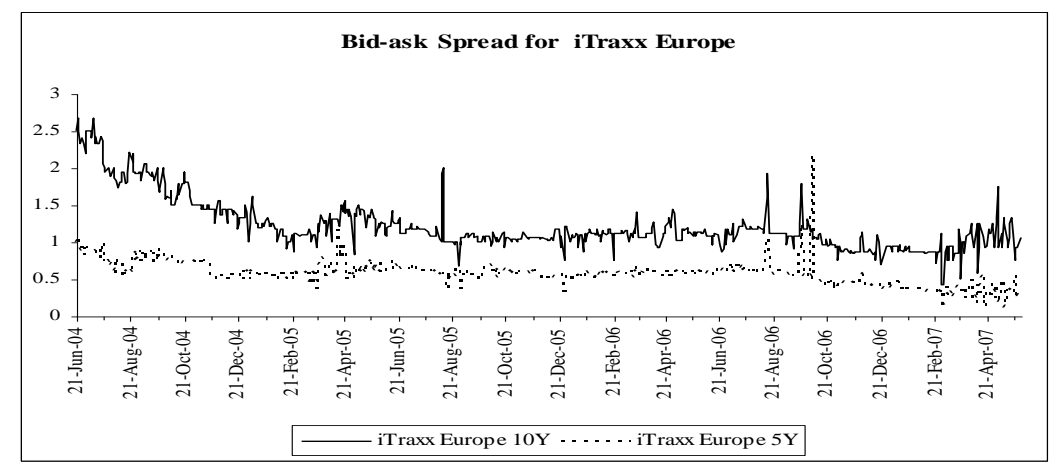

Panel A. iTraxx Europe

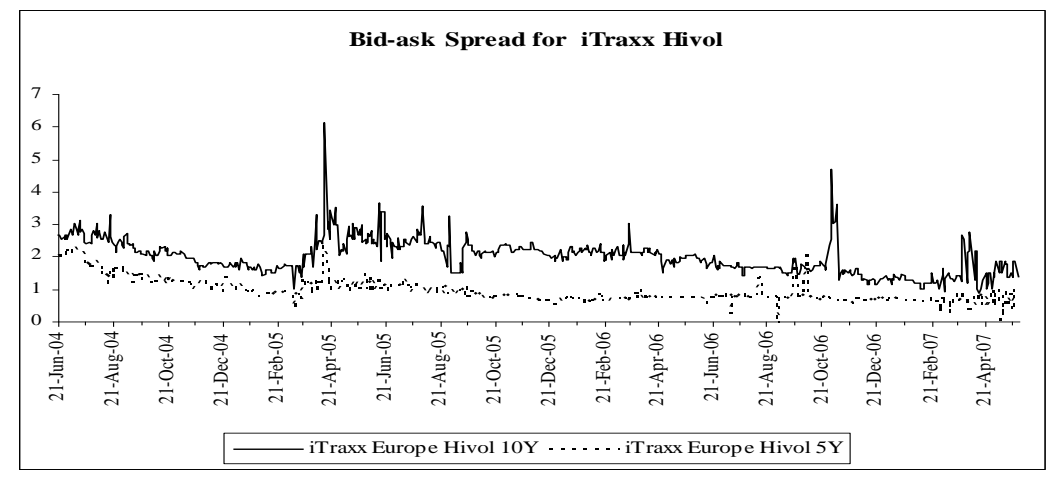

Panel B. iTraxx Europe Hivol

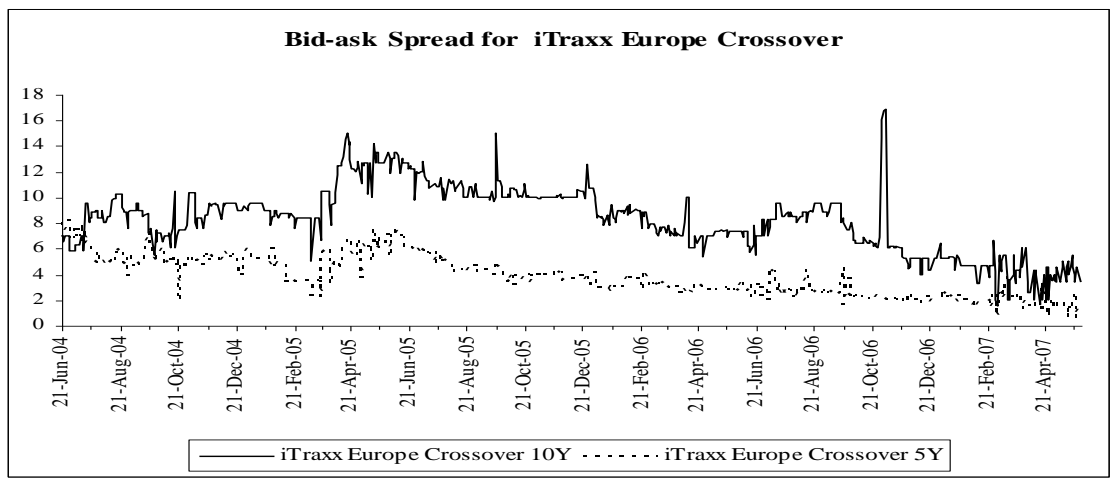

Panel C. iTraxx Europe Crossover

Figure 6. Bid-ask spread for iTraxx index (natural logarithm of bid-ask basis points difference) 
The persistent component $X_{2}$ is assumed to follow a Brownian motion with deterministic drift. For ease of estimation, we assume the noise term $\varepsilon_{i, t}$ is independent of $d W_{1}$ and $d W_{2}$, but $d W_{1}$ and $d W_{2}$ are correlated with correlation $\rho$; that is $d W_{1} d W_{2}=\rho d t$.

The state variable $X_{1}$ may be related to transitory market factors such as noise and feedback trading as can happen in the stock market. As a result, changes in the temporary component represent short-term changes in prices that are not expected to persist, while changes in the persistent component represent fundamental, long-term changes that are expected to persist.

We rewrite our continuous-time model in discrete form based on the measurement interval $\Delta t$. So, for equation (4) we get,

$$
\begin{aligned}
& \Delta X_{1, t}=-k X_{1, t-1} \Delta t+\sigma_{1} \Delta Z_{1} \\
& X_{1, t}-X_{1, t-1}=-k X_{1, t-1} \Delta t+\sigma_{1} \Delta Z_{1} \\
& X_{1, t}=(1-k \Delta t) X_{1, t-1}+\sigma_{1} \Delta Z_{1}
\end{aligned}
$$

Similarly, we can transform equation (5) and get

$$
\begin{aligned}
& \Delta X_{2}=\mu \Delta t+\sigma_{2} \Delta Z_{2} \\
& X_{2, t}-X_{2, t-1}=\mu \Delta t+\sigma_{2} \Delta Z_{2} \\
& X_{2, t}=X_{2, t-1}+\mu \Delta t+\sigma_{2} \Delta Z_{2}
\end{aligned}
$$

If we express it in matrix form, then we get

$$
\begin{gathered}
{\left[\begin{array}{l}
X_{1, t} \\
X_{2, t}
\end{array}\right]=\left[\begin{array}{c}
0 \\
\mu \Delta t
\end{array}\right]+\left[\begin{array}{cc}
1-k \Delta t & 0 \\
0 & 1
\end{array}\right] \times\left[\begin{array}{l}
X_{1, t-1} \\
X_{2, t-1}
\end{array}\right]+\left[\begin{array}{l}
v_{1, t} \\
v_{2 . t}
\end{array}\right]} \\
{\left[\begin{array}{l}
v_{1, t} \\
v_{2, t}
\end{array}\right] \sim N\left[\begin{array}{l}
0 \\
0
\end{array}, \Omega\right], \Omega=\left[\begin{array}{cc}
\sigma_{1}^{2} & \rho \sigma_{1} \sigma_{2} \\
\rho \sigma_{1} \sigma_{2} & \sigma_{2}^{2}
\end{array}\right] \Delta t}
\end{gathered}
$$

The parameter set is

$$
\Theta \equiv\left\{k, \sigma_{1}, \sigma_{2}, \mu, \rho, a, b, d, \sigma_{1, \varepsilon}, \sigma_{2, \varepsilon}\right\}
$$




\section{Macrothink}

The measurement equation (3) and the state dynamics (10) may be cast into State Space framework, and we get:

$$
\begin{gathered}
Y_{t}=H \times S_{t}+W_{t}, W_{t} \sim N(0, R) \\
S_{t}=J+F \times S_{t-1}+V_{t}, V_{t} \sim N(0, Q)
\end{gathered}
$$

where,

$S_{t}=\left[\begin{array}{l}X_{1, t} \\ X_{2, t}\end{array}\right], J=\left[\begin{array}{c}0 \\ \mu \Delta t\end{array}\right], F=\left[\begin{array}{cc}1-k \Delta t & 0 \\ 0 & 1\end{array}\right], H=\left[\begin{array}{ll}1 & 1 \\ 1 & d\end{array}\right], Y_{t}=\left[\begin{array}{c}C D S_{t}^{5} \\ C D S_{t}^{10}\end{array}\right] ; \quad R=\left[\begin{array}{cc}\sigma_{1, \varepsilon}^{2} & 0 \\ 0 & \sigma_{2, \varepsilon}^{2}\end{array}\right]$, and $Q=\Omega$ as defined in equation (11).

\subsubsection{State-Space Model and the Kalman Filter}

State-space frameworks typically deal with dynamic time series models that involve unobserved components and are becoming more widespread in applied econometric and financial applications. Compared with the multivariate regression models, the state-space model does not require an a priori specification of the predictive variables [Zhou and Qing (2000)]. In the literature, considerable effort has been devoted to empirically model the underlying factors describing the dynamic behaviour of asset prices. The basic estimation tool used to deal with the standard state-space model is the Kalman filter. The Kalman filter is a recursive procedure for computing optimal estimates of unobserved state variables at time $t$ based on available information at time $t$. Given an a priori distribution on the initial value of the state variables and a model describing the likelihood of the observations as a function of the true value, the Kalman filter generates updated posterior distributions for these state variables in accordance with Bayes' rule. The modelling of time series in state-space form has advantages over other techniques both in interpretability and estimation.

The Kalman filter recursive formulas for our model, as presented in Harvey (1989), are described by following set of equations:

$$
\begin{gathered}
S_{t \mid t-1}=J+F S_{t-1 \mid t-1} \\
P_{t \mid t-1}=F \times P_{t-1 \mid t-1} \times F^{\prime}+Q \\
\Psi=H \times P_{t \mid t-1} H^{\prime}+R \\
S_{t \mid t}=S_{t \mid t-1}+P_{t \mid t-1} \times H \times \Psi^{-1}\left(Y_{t}-H^{\prime} \times S_{t \mid t-1}\right) \\
\xi_{t}=Y_{t}-H^{\prime} \times S_{t \mid t-1}
\end{gathered}
$$




$$
P_{t \mid t}=P_{t \mid t-1}-P_{t \mid t-1} H H^{\prime} P_{t \mid t-1} \Psi^{-1}
$$

The log-likelihood function is given below:

$$
L n L=-\frac{n T}{2} \operatorname{Ln}(2 \pi)-\frac{1}{2} \sum_{t=1}^{T} \operatorname{Ln}\left(\operatorname{det}\left(\Psi_{t}\right)\right)-\frac{1}{2} \sum_{t=1}^{T} \xi_{t}^{\prime} \Psi_{t}^{-1} \xi_{t}
$$

\subsubsection{Linear Regression Model for the Determinant of CDS Components}

We use a regression technique to examine the possible relationships between the temporary component and persistent component extracted from the iTraxx indices and the potential drivers, namely the short-term interest rate, the slope of the yield curve, equity volatility, liquidity (i.e. the bid-ask spread) and credit rating premia.

The specific regression model is as below.

$$
\begin{aligned}
& \text { dependent }=\alpha+\beta_{1} \cdot \text { short rate }+\beta_{2} \cdot \text { yield slope }+\beta_{3} \cdot \text { volatility } \\
& +\beta_{4} \cdot \text { illiquidity }+\beta_{5} \cdot \text { credit premium }+e
\end{aligned}
$$

where

dependent : Time series of interest, for example, the logarithm of 5-year iTraxx Europe or its components, etc

$e:$ Error term in regression model.

All these explanatory variables and their potential influences have been discussed in an intuitive manner in an earlier section. In the next section we will discuss the model's estimated parameters as well as the nature of the inferred components of the CDS series.

\section{Empirical Results}

In this section we provide the main results and analysis of these results.

\subsection{Estimation Results for the Component Structure}

The adaptive filtering algorithm due to Kalman allows us to estimate the unknown parameters of the model by maximising the log likelihood function identified in equation (21). At the same time, it produces optimal inference about the state variables. These filtered state variables are our extracted components consistent with the dynamic specification of the model. 


\section{Macrothink}

International Journal of Accounting and Financial Reporting ISSN 2162-3082 2018, Vol. 8, No. 4

Table 4. Estimated results for Schwartz and Smith (2000) two-factor model

\begin{tabular}{|c|c|c|c|}
\hline & iTraxx Europe & iTraxx Hivol & $\begin{array}{l}\text { iTraxx } \\
\text { Crossover }\end{array}$ \\
\hline \multirow[t]{2}{*}{$k$} & 0.0645 & 0.08791 & 0.0071 \\
\hline & $(1.0558 \mathrm{e}-05)$ & $(3.4554 \mathrm{e}-10)$ & $(0.1106)$ \\
\hline \multirow[t]{2}{*}{$\mu$} & -0.3360 & -0.2599 & -0.3537 \\
\hline & $(2.5209 \mathrm{e}-06)$ & $(1.1254 \mathrm{e}-10)$ & $(0.0259)$ \\
\hline \multirow{2}{*}{$\sigma_{1}$} & 0.2413 & 0.3085 & 0.3321 \\
\hline & $(0.0004)$ & $(3.9884 \mathrm{e}-08)$ & $(0.0019)$ \\
\hline \multirow[t]{2}{*}{$\sigma_{2}$} & 0.2527 & 0.1741 & 0.2087 \\
\hline & $(0.0001)$ & $(1.2685 \mathrm{e}-07)$ & $(0.0009)$ \\
\hline \multirow[t]{2}{*}{$d$} & 0.3792 & 0.1382 & 0.4155 \\
\hline & $(4.6337 \mathrm{e}-05)$ & $(4.4952 \mathrm{e}-06)$ & $(0.0076)$ \\
\hline \multirow[t]{2}{*}{$\rho$} & 0.1322 & 0.5954 & 0.5064 \\
\hline & $(0.0003)$ & $(2.7771 \mathrm{e}-10)$ & $(0.0126)$ \\
\hline \multirow[t]{2}{*}{$a$} & 1.8004 & 2.3572 & 3.72658 \\
\hline & $(1.4920 \mathrm{e}-05)$ & $(1.4121 \mathrm{e}-10)$ & $(6.99288 \mathrm{e}-06)$ \\
\hline \multirow[t]{2}{*}{$b$} & 2.6774 & 3.4004 & 4.34888 \\
\hline & $(5.8563 \mathrm{e}-06)$ & $(4.6739 \mathrm{e}-06)$ & $(0.00788)$ \\
\hline$\sigma_{1, \varepsilon}$ & $7.3658 \mathrm{e}-06$ & $1.0000 \mathrm{e}-10$ & $2.4998 \mathrm{e}-05$ \\
\hline
\end{tabular}


$(6.0727 \mathrm{e}-11) \quad(3.0614 \mathrm{e}-10) \quad(1.3065 \mathrm{e}-10)$

\begin{tabular}{llll}
\hline$\sigma_{2, \varepsilon}$ & $1.0000 \mathrm{e}-10$ & $2.8374 \mathrm{e}-05$ & $2.8588 \mathrm{e}-06$ \\
\hline & $(2.5993 \mathrm{e}-11)$ & $(2.2415 \mathrm{e}-10)$ & $(3.3042 \mathrm{e}-11)$ \\
\hline $\begin{array}{l}\text { Log-likelihood } \\
\text { function }\end{array}$ & 4654.8879 & 4315.0815 & 4379.8852 \\
\hline
\end{tabular}

Note: Asymptotic estimator variance is reported below each estimated parameter. Here we adopt BHHH estimator as variance estimators for an MLE. More detail information may be found in William H. Greene, "Econometric Analysis" fifth edition, P480-P482.

Table 4 lists the estimation results for our two component models along with the asymptotic standard errors in parentheses. Firstly, for iTraxx Europe and iTraxx Europe Hivol, all parameter estimates are significant except for the variance of the measurement equation for $\mathrm{CDS}^{5}$ for iTraxx Europe Hivol. The fact that all the measurement equation error variances are very small is indicative of the appropriateness of the model specification. The estimated values for $\kappa$, the speed of mean reversion for the transient component, are $6.45 \%$ per annum for iTraxx Europe and $8.791 \%$ per annum for iTraxx Europe Hivol. For iTraxx Europe Crossover it is only $0.71 \%$ and is not statistically significant. This means that there is no mean-reversion in the transient component of iTraxx Europe Crossover. This different behaviour should not be surprising, as this is the index for sub-investment grade firms. The transient component of the Crossover index demonstrates a more diffusive characteristic.

We now focus on the fact that the estimation results for $\mu$, the drift term in the persistent component, are all negative and statistically significant. Negative drift indicates a downward trend in this component of the iTraxx index over the sample period. This is consistent with the original observation of these index time series. The annual drifts for iTraxx Europe, iTraxx Europe Hivol and iTraxx Europe Crossover are $-0.3360,-0.2599$ and -0.3537 , respectively. We believe that this downward trend is mainly due to the increasing sophistication of the credit default swap market as well as enhanced liquidity and efficiency during our sample period. It makes intuitive sense that such a systemic characteristic would be captured by the persistent component of the CDS spreads.

Next, we turn to the diffusion coefficients. The diffusion coefficients for the transient components for iTraxx Europe, iTraxx Europe Hivol and iTraxx Europe Crossover are $0.2413,0.3085$ and 0.3321 . The corresponding figures for the persistent components are $0.2527,0.1741$, and 0.2087 . We can make some qualitative assessment of the fact that the diffusion coefficients, $\sigma_{1}$, for the transient components for iTraxx Europe Hivol and iTraxx Europe Crossover are higher than that of iTraxx Europe as a whole. This is possibly due to the fact that the credit default swap spreads with underlying entities having lower credit 
ratings are more sensitive to market news in the short term. However, from a longer term perspective, the lower credit rating firms have milder variations. The firms that are already on lower credit ratings have less probability of downgrading, in the longer term, compared with those of high credit rating firms. So, from this point of view, the diffusion coefficients of the persistent components, $\sigma_{2}$, of iTraxx Europe Hivol and iTraxx Europe Crossover should be lower than that of iTraxx Europe. This is what the estimated results demonstrate.

Furthermore, comparing within each of the three benchmark iTraxx indices, the volatility of the persistent components of iTraxx Europe Hivol and iTraxx Europe Crossover is smaller than that of the respective transient components. The persistent components are less likely to be influenced by market news and events of short-term in nature. The differences in the volatility level of the two components for iTraxx Europe are only marginal. The reason for this is that this series includes more of the firms that belong to higher credit rating categories.

The differences in the pattern of behaviour of the two components of the CDS spread series are quite instructive, and without such decomposition it would be hard to get such in-depth understanding. Last but not least, it is interesting to note that all the measurement error variances, $\sigma_{1, \varepsilon}$ and $\sigma_{2, \varepsilon}$, are quite small, indicating the efficacy of the model. Figure 7 plots the two extracted components for each of the series against time.

\subsection{Exploring the Determinants of the Components}

In this section we analyse the explanatory power of several variables suggested in the literature for the components as well as for the original CDS spread series itself. This helps us understand the differences in the impact these variables have while reconciling some of the conflicting results reported in the literature where such a component approach is not implemented. This analysis is carried out in a linear regression framework consistent with the reported studies in this area. In some cases we may have non-stationary series on both sides of the regression equation, but it does not necessarily make the results spurious. As long as the regression residuals are stationary the usual implications of t- and F- tests and R-squares are applicable [see Gujarati (2004), page 822-824].

Table 5 lists the estimation results for the explanatory regressions along with the robust standard errors in parentheses below each parameter estimate. The explanatory power of the theoretical variables for levels of default swap spreads are high, with R-square approximately $70 \%$, which is consistent with Ericsson et al (2005) and Abid et al (2006). Ericsson et al. (2005) find the explanatory power of the theoretical variables for levels of default swap spreads is approximately $60 \%$, and they also point out that the R-square for levels regressions goes up to more than $70 \%$ if we add in other explanatory variables as in Collin-Dufresne, Goldstein and Martin (2001).

From Table 5 we find that the robust R-square is highest when we regress the persistent component against all those explanatory variables. The regression residuals are all found to be stationary. Firstly, the explanatory power of these traditional variables for the persistent 
component is more than $80 \%$ and is much higher than that of the transient component, which is around 50\%. Secondly, we notice that since most of the parameters are significant, it implies that the explanatory variables employed here have valuable information for predicting movement in credit default swap spreads. Again, the higher robust R-square seems to show that the traditional explanatory variables can explain more about the persistent component of CDS spreads extracted from the original data relative to the transient component. Next, we take a detailed look at these results.

Table 5. Estimation results for regression model

Panel a: Dependent variable: iTraxx Europe

\begin{tabular}{|c|c|c|c|c|}
\hline & $5 \mathrm{Y}$ & $10 \mathrm{Y}$ & $\begin{array}{l}\text { Temporary } \\
\text { component }\end{array}$ & $\begin{array}{l}\text { Persistent } \\
\text { component }\end{array}$ \\
\hline \multirow[t]{2}{*}{$\alpha$} & $3.9012^{* * *}$ & $4.8587^{* * *}$ & $1.6975^{* * *}$ & $0.4894^{* * *}$ \\
\hline & $(0.1128)$ & $(0.0869)$ & $(0.0996)$ & $(0.0450)$ \\
\hline \multirow[t]{2}{*}{$\beta_{1}$} & $-1.0319^{* * *}$ & $-0.9769^{* * *}$ & $-0.7618^{* * *}$ & $-0.3982^{* * *}$ \\
\hline & $(0.0374)$ & $(0.0346)$ & $(0.0337)$ & $(0.0207)$ \\
\hline \multirow[t]{2}{*}{$\beta_{2}$} & $-0.0918^{* * *}$ & $-0.2920^{* * *}$ & $-0.2666^{* * *}$ & $0.1088^{* * *}$ \\
\hline & $(0.0178)$ & $(0.0199)$ & $(0.0188)$ & $(0.0117)$ \\
\hline \multirow[t]{2}{*}{$\beta_{3}$} & $21.3165^{* * *}$ & $16.2558^{* * *}$ & $14.1927^{* * *}$ & $6.2780^{* * *}$ \\
\hline & $(2.4143)$ & $(2.7215)$ & $(2.7101)$ & $(0.7138)$ \\
\hline \multirow[t]{2}{*}{$\beta_{4}$} & $0.0757^{* * *}$ & $0.1258^{* * *}$ & $0.0299^{* *}$ & $0.1106^{* * *}$ \\
\hline & $(0.0128)$ & $(0.0196)$ & $(0.0114)$ & $(0.0148)$ \\
\hline \multirow[t]{2}{*}{$\beta_{5}$} & $0.2596^{* * *}$ & 0.0651 & $0.0890^{* *}$ & $0.2196^{* * *}$ \\
\hline & $(0.0522)$ & $(0.0452)$ & $(0.0422)$ & $(0.0223)$ \\
\hline $\mathrm{R}^{2}$ & 0.8405 & 0.6684 & 0.4413 & 0.9256 \\
\hline
\end{tabular}


Panel b: Dependent variable: iTraxx Hivol(continued)

\begin{tabular}{|c|c|c|c|c|}
\hline & $5 \mathrm{Y}$ & $10 \mathrm{Y}$ & $\begin{array}{l}\text { Temporary } \\
\text { component }\end{array}$ & $\begin{array}{l}\text { Persistent } \\
\text { component }\end{array}$ \\
\hline \multirow[t]{2}{*}{$\alpha$} & $4.7110^{* * *}$ & $5.3324^{* * *}$ & $1.7042^{* * *}$ & $0.6155^{* * *}$ \\
\hline & $(0.1627)$ & $(0.1016)$ & $(0.1265)$ & $(0.0465)$ \\
\hline \multirow[t]{2}{*}{$\beta_{1}$} & $-1.5296^{* * *}$ & $-0.9635^{* * *}$ & $-1.1917^{* * *}$ & $-0.3127^{* * *}$ \\
\hline & $(0.0489)$ & $(0.0454)$ & $(0.0396)$ & $(0.0227)$ \\
\hline \multirow[t]{2}{*}{$\beta_{2}$} & $-0.3439^{* * *}$ & $-0.4009^{* * *}$ & $-0.4086^{* * *}$ & $0.0852^{* * *}$ \\
\hline & $(0.0326)$ & $(0.0174)$ & $(0.0254)$ & $(0.0084)$ \\
\hline \multirow[t]{2}{*}{$\beta_{3}$} & $29.1548^{* * *}$ & $17.6193^{* * *}$ & $20.1077^{* * *}$ & $9.6246^{* * *}$ \\
\hline & $(2.7971)$ & $(2.3884)$ & $(2.4564)$ & $(0.7105)$ \\
\hline \multirow[t]{2}{*}{$\beta_{4}$} & 0.0403 & $0.2396^{* * *}$ & 0.0085 & $0.0176^{*}$ \\
\hline & $(0.0254)$ & $(0.0286)$ & $(0.0171)$ & $(0.0091)$ \\
\hline \multirow[t]{2}{*}{$\beta_{5}$} & $0.4387^{* * *}$ & 0.0631 & $0.2942^{* * *}$ & $0.1498^{* * *}$ \\
\hline & $(0.0675)$ & $(0.0496)$ & $(0.0515)$ & $(0.0258)$ \\
\hline $\mathrm{R}^{2}$ & 0.7038 & 0.6338 & 0.5335 & 0.8640 \\
\hline
\end{tabular}

Panel c: Dependent variable: iTraxx Europe Crossover (continued)

\begin{tabular}{lllll}
\hline & $5 \mathrm{Y}$ & $10 \mathrm{Y}$ & $\begin{array}{l}\text { Temporary } \\
\text { component }\end{array}$ & $\begin{array}{l}\text { Persistent } \\
\text { component }\end{array}$ \\
\hline$\alpha$ & $3.6103^{* * *}$ & $4.252241^{* * *}$ & -0.0872 & 0.0936 \\
\hline & $(0.1133)$ & $(0.120182)$ & $(0.0921)$ & $(0.0677)$ \\
\hline
\end{tabular}




\begin{tabular}{|c|c|c|c|c|}
\hline$\beta_{1}$ & $-0.9257^{* * *}$ & $-0.6281^{* * *}$ & $-0.5614^{* * *}$ & $-0.2419^{* * *}$ \\
\hline & $(0.0389)$ & $(0.0464)$ & $(0.0300)$ & $(0.0309)$ \\
\hline \multirow[t]{2}{*}{$\beta_{2}$} & $-0.1017^{* * *}$ & $-0.1620^{* * *}$ & $-0.2707^{* * *}$ & $0.1794^{* * *}$ \\
\hline & $(0.0187)$ & $(0.0178)$ & $(0.0167)$ & $(0.0117)$ \\
\hline \multirow[t]{2}{*}{$\beta_{3}$} & $21.1169^{* * *}$ & $20.3619^{* * * *}$ & $10.2978^{* * *}$ & $13.7750^{* * *}$ \\
\hline & $(2.5014)$ & $(2.6043)$ & $(1.9587)$ & $(1.1726)$ \\
\hline \multirow[t]{2}{*}{$\beta_{4}$} & $0.1136^{* * *}$ & $0.1169^{* * *}$ & $0.0793^{* * *}$ & $0.0716^{* * *}$ \\
\hline & $(0.0180)$ & $(0.0173)$ & $(0.0174)$ & $(0.0074)$ \\
\hline \multirow[t]{2}{*}{$\beta_{5}$} & $1.2648^{* * *}$ & $1.0221^{* * *}$ & $0.8761^{* * *}$ & $0.2333^{* * *}$ \\
\hline & $(0.0439)$ & $(0.0454)$ & $(0.0361)$ & $(0.0346)$ \\
\hline $\mathrm{R}^{2}$ & 0.7645 & 0.6807 & 0.7369 & 0.8637 \\
\hline
\end{tabular}

Note: 1 . The model provided in this table is

$$
\begin{array}{r}
\text { dependent }=\alpha+\beta_{1} \cdot \text { riskfree rate }+\beta_{2} \cdot \text { yield slope }+\beta_{3} \cdot \text { volatility } \\
+\beta_{4} \cdot \text { illiquidity }+\beta_{5} \cdot \text { credit premium }+\varepsilon
\end{array}
$$

We use Stata command "regress, robust" and the robust standard error is proved in parentheses below each estimator and robust $\mathrm{R}^{2}$ is provided as well.

2. $1 \%, 5 \%$ and $10 \%$ significance levels are indicated by ${ }^{* * *},{ }^{* *}$, and ${ }^{*}$, respectively.

To the extent that the CDS spread indices for two maturities (5-year and 10-year) are valued in the market with respect to the economic fundamentals, we would expect the estimated result for the transient component to be more akin to that of the 5-year maturity index. Similarly, we expect the result for the persistent component to be more like that of the 10-year maturity index. We can verify this by checking their relative sensitivity to different explanatory variables. For example, iTraxx Europe $5 \mathrm{Y}$ is more sensitive to the short-term interest rate than iTraxx Europe 10Y. We would thus expect the transient component to be more sensitive to the short-term interest rate than the persistent component, and vice versa. Not surprisingly, the estimated results do support our hypothesis and provide evidence of 
support for our modelling approach. To be precise, the absolute value of $\beta_{1}$ is larger for all three iTraxx 5Y series than for its counterpart iTraxx 10Y series, and it is also larger for the transient component compared to the persistent component.

Most of our results (from Table 5) are consistent with those published in related studies. For example, let us examine the negative relationship between CDS and the short-term interest rate. As we would expect, the short-term interest rate has more impact on the transient component. The result also supports the proposition that the CDS spread is positively correlated with equity market volatility. Again, the corresponding coefficient of equity volatility confirms our hypothesis that this has more influence on the transient component. All the coefficients for the short-term interest rate and equity market volatility are statistically significant at the $1 \%$ level of significance.

Our results also suggest that illiquidity may cause higher CDS spread levels indicated by a positive coefficient for the liquidity proxy $\beta_{4}$. But when we compare the extent of its impact on the two components, we find that it has more influence on the persistent component, implying that the influence of illiquidity is quite persistent. However, for sub-investment grade firms, the influence of this factor does not vary greatly between the transient and the persistent components. This is due to the fact that the CDSs whose underlying firms have lower credit ratings are not affected as strongly by market liquidity as by other influential elements. This result can also be verified by comparing the robust R-square for the regression model without a liquidity proxy. After omitting the liquidity proxy from the model for the transient component of iTraxx Europe Crossover, the adjusted R-square only decreases by 0.0016 to 0.7235 . But when we omit the other variables, for example, the proxy of credit premia, the adjusted R-square sharply decreases by 0.2378 to 0.4973 . To conserve space we have not presented these results in the tables, but they are available on request.

Another set of interesting parameters to examine are $\beta_{2}$ and $\beta_{5}$, the coefficients for the slope of the yield curve and the credit rating premia, respectively. For all three iTraxx benchmark indices, the coefficients of the slope of the yield curve are positive for the persistent component, but negative for the transient component. For each individual index this coefficient is negative. For example, $\beta_{2}$ is 0.1088 and statistically significant for the persistent component of iTraxx Europe, while it is negative for all other three counterpart regressions. That is, $\beta_{2}$ is -0.2666 for the transient component (iTraxx Europe), -0.0918 in iTraxx Europe 5Y and -0.2920 in iTraxx Europe 10Y. As we have explained in section 3.1.2 above, the slope of the yield curve is as an indication of overall economic health. Theoretically, an increase in the slope of the yield curve should increase the expected future short-term interest rate and result in a decrease in the CDS spread if the negative relation between credit risk and the short-term interest rate holds. 
But the influence of the slope is quite clear and consistent in our results based on our component methodology. For example, the absolute values of $\beta_{2}$, which can be interpreted as the extent of influence, in iTraxx index regressions are quite close, but are different in the two component-based regressions. The same pattern can be found in all three iTraxx indices. So the results in this paper provide clear evidence that the slope of the yield curve affects the two components differently. Without these component distinctions the impact of the slope on CDS could turn out to be conflicting, as in Avramov et al. (2007). With a long-term perspective, the increased slope indicates a higher long-term rate, all else being equal, which implies higher borrowing costs and hence increases the credit default swap spread. This is reflected in the persistent component. On the other hand, a higher slope means a higher expected future short rate, which is negatively related to credit default swap spreads and especially to the transient component. We found a negative coefficient of slope of yield curve for the transient components.

The credit rating premium is another explanatory variable developed in this paper in order to capture the influence of credit rating. The positive coefficient is quite intuitive. This relationship does not appear to be significant for iTraxx Europe 10Y and iTraxx Hivol Europe 10Y. Our assertion is that the reason is that the CDS spread increases with time to maturity, and long-term CDS is not as sensitive to rating premia as short-term CDS. In other words, the relative higher level of long-term CDS resulting from long-term maturity is not so sensitive to temporary fluctuation in rating premia. When we look back to Figure 3 , we find that the credit rating premia for 10- year maturity contracts are much lower than the credit rating premia for 5-year maturity contracts. As we would expect, the importance of credit rating premia (captured by the parameter $\beta_{5}$ ) increases as lower credit rated entities are included in the series and in particular for the transient components.

We now turn to the explanatory variable spread as well as Table 7. In this table, we list the estimated results for regression models just omitting the credit rating premia. Most parameter estimates are statistically significant under the $1 \%$ significant level. The important information that can be gleaned from Table 7 is that it confirms that credit rating premia are more of concern for the transient component, especially with lower credit rating entities in the CDS index. For example, there is not much deterioration in R-square in the case of any of the persistent components. But for iTraxx Crossover the R-square drops from 73.69\% (Table 5) to $49.99 \%$ (Table 6) for the transient component.

The results clearly show that the robust R-square without credit rating premia (Table 6) does not change much for both the transient and the persistent components of iTraxx Europe. But it does change for the other two iTraxx indices and especially for iTraxx Europe Crossover, which is the index with the lowest credit rating. So, this result confirms the argument that we put forward in earlier section, that for CDS spreads with higher credit rating underlying entities, credit rating has only a marginal difference in impact for the two components; while for CDS spreads with lower credit rating underlying entities, the credit rating impact differs depending on the components. 
Table 6. Estimation results for regression model

\begin{tabular}{|c|c|c|c|c|c|c|}
\hline & \multicolumn{2}{|c|}{ iTraxx Europe } & \multicolumn{2}{|c|}{ iTraxx Europe Hivol } & \multirow{2}{*}{$\begin{array}{l}\begin{array}{l}\text { iTraxx } \\
\text { Crossover }\end{array} \\
\begin{array}{l}\text { Temporary } \\
\text { component }\end{array}\end{array}$} & \multirow{2}{*}{$\begin{array}{r}\text { Europe } \\
\begin{array}{l}\text { Persistent } \\
\text { componen }\end{array}\end{array}$} \\
\hline & $\begin{array}{l}\text { Temporary } \\
\text { component }\end{array}$ & $\begin{array}{l}\text { Persistent } \\
\text { component }\end{array}$ & $\begin{array}{l}\text { Temporary } \\
\text { component }\end{array}$ & $\begin{array}{l}\text { Persistent } \\
\text { component }\end{array}$ & & \\
\hline \multirow[t]{2}{*}{$\alpha$} & $1.8728^{* * *}$ & $0.8769^{* * *}$ & $2.3107^{* * *}$ & $0.8375^{* * *}$ & $1.4836^{* * *}$ & $0.4062^{* * *}$ \\
\hline & 0.0367 & 0.0268 & 0.0589 & 0.0259 & 0.0670 & 0.0436 \\
\hline \multirow[t]{2}{*}{$\beta_{1}$} & $-0.7402^{* * *}$ & $-0.3677^{* * *}$ & $-1.1573^{* * *}$ & $-0.2648^{* * *}$ & $-0.3362^{* * *}$ & $-0.1601^{* * *}$ \\
\hline & 0.0354 & 0.0212 & 0.0425 & 0.0211 & 0.0460 & 0.0289 \\
\hline \multirow[t]{2}{*}{$\beta_{2}$} & $-0.2797^{* * * *}$ & $0.0729^{* * *}$ & $-0.4676^{* * *}$ & $0.0693^{* * *}$ & $-0.4066^{* * *}$ & $0.1597^{* * *}$ \\
\hline & 0.0157 & 0.0126 & 0.0264 & 0.0085 & 0.0200 & 0.0116 \\
\hline \multirow[t]{2}{*}{$\beta_{3}$} & $14.4515^{\text {*** }}$ & $6.9112^{* * *}$ & $21.5621^{* * *}$ & $9.7720^{* * *}$ & $14.6423^{* * *}$ & $14.9572^{* * *}$ \\
\hline & 2.7329 & 0.7847 & 2.6707 & 0.7324 & 2.8155 & 1.3038 \\
\hline \multirow[t]{2}{*}{$\beta_{4}$} & $0.0390^{* * *}$ & $0.1252^{* * *}$ & 0.0312 & $0.0385^{* * *}$ & $0.1415^{* * *}$ & $0.0894^{* * *}$ \\
\hline & 0.0118 & 0.0166 & 0.0246 & 0.0097 & 0.0265 & 0.0085 \\
\hline $\mathrm{R}^{2}$ & 0.4369 & 0.9142 & 0.5048 & 0.8557 & 0.4999 & 0.8523 \\
\hline
\end{tabular}

Note: 1 . The model provided in this table is

dependent $=\alpha+\beta_{1} \cdot$ riskfree rate $+\beta_{2} \cdot$ yield slope $+\beta_{3} \cdot$ volatility $+\beta_{4} \cdot$ illiquidity $+\varepsilon$

We use Stata command "regress, robust" and the robust standard error is proved in parentheses below each estimator and robust $\mathrm{R}^{2}$ is provided as well.

2. $1 \%, 5 \%$ and $10 \%$ significance levels are indicated by ${ }^{* * * * *}$, and ${ }^{*}$, respectively. 


\section{Conclusion}

Credit risk analysis is important for valuing corporate bonds, swaps and credit derivatives and plays a critical role in managing the credit risk of bank loan portfolios. Generally, it is argued that credit derivatives (especially credit default swaps) are a much better proxy for credit risk, since the majority of fundamental variables predicted by credit risk pricing theories have a significant influence on credit default swap prices.

The ideas put forward in this paper are quite innovative and can provide some ideas for later research on the credit derivatives market. The estimated results in this paper are consistent. Firstly, we extracted information from the original data using the latent two-factor model used in Schwartz and Smith (2000) and obtained a temporary component and a persistent component. The intuition behind this was that we extracted latent factors which have different movements over time, in order to classify different information sets. The results from our latent factor model showed that this model is realistic and agrees with our original information. We then took a deep look at the different influences of theoretical credit risk explanatory variables on CDS indices and both their temporary and persistent components.

The estimations from our latent factor model and multi-factor linear regression model show that the temporary component does behave differently from the persistent component and that these theoretical explanatory variables do have different influences both in direction and degree on the temporary component and the persistent component. For example, equity volatility seems to have a larger influence on the transitory component, suggesting that its effect may be mostly short-lived, while our proxy for illiquidity has a bigger impact on the persistent component, which suggests that its effect is more enduring. Surprisingly, our proxy for the credit rating premium is not even significant in explaining two of the 10-year indices, but has a large effect on the persistent component. Finally, the slope of the yield curve has impacts with opposite signs on the two components and thus helps address the conflicting results reported in earlier studies without such a component framework. These results indicate that a two factor formulation, similar to the Hull and White (1994) interest rate model, may be needed to model CDS options. Furthermore, the regression results show that the theoretical explanatory variables can explain more for the persistent component.

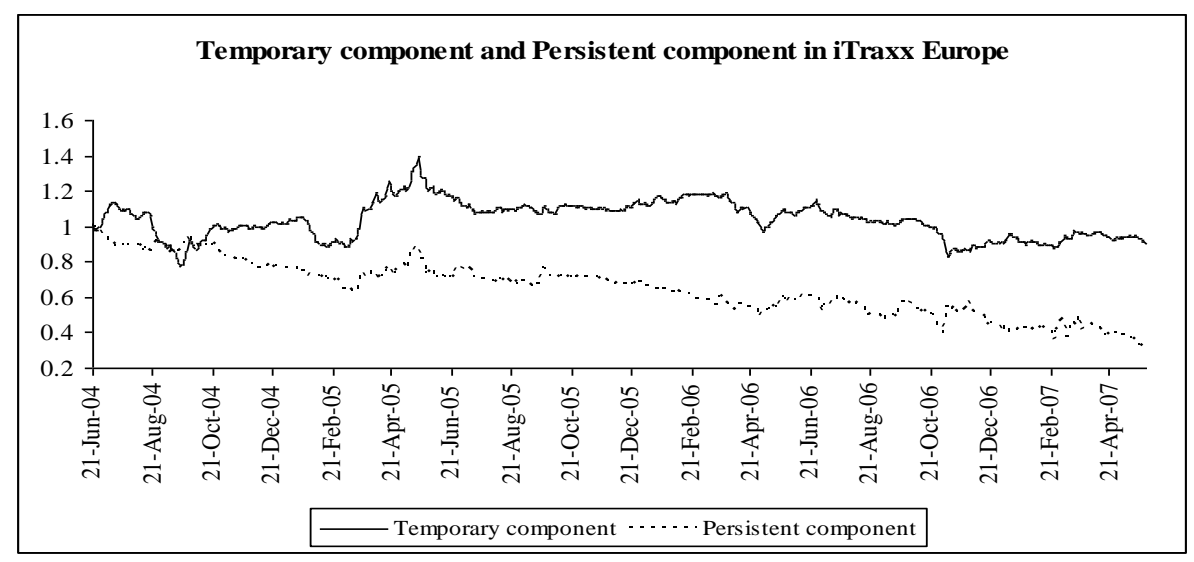

Panel A. Temporary component and persistent component for iTraxx Europe 


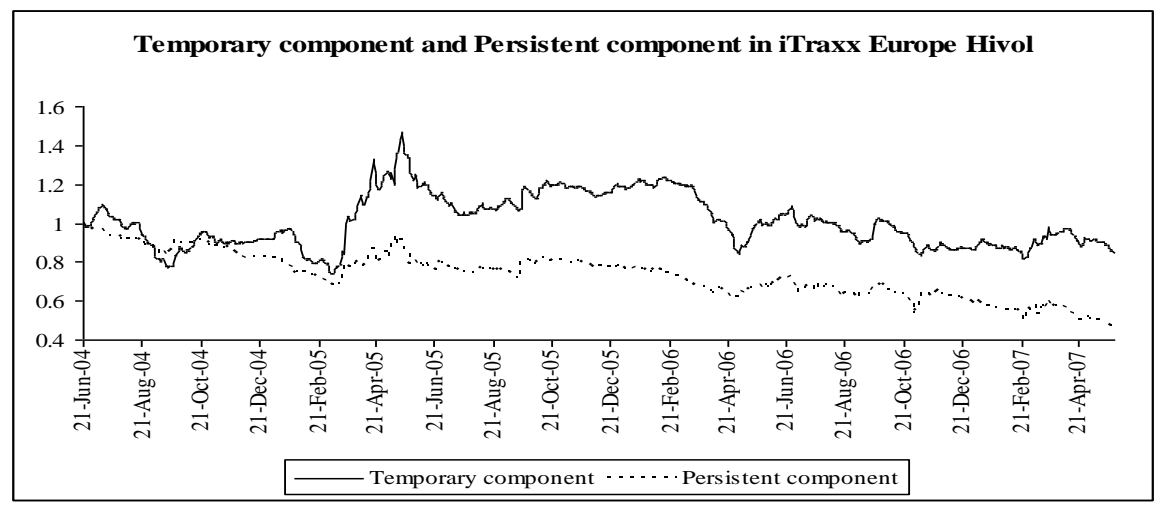

Panel B. Temporary component and persistent component for iTraxx Europe Hivol

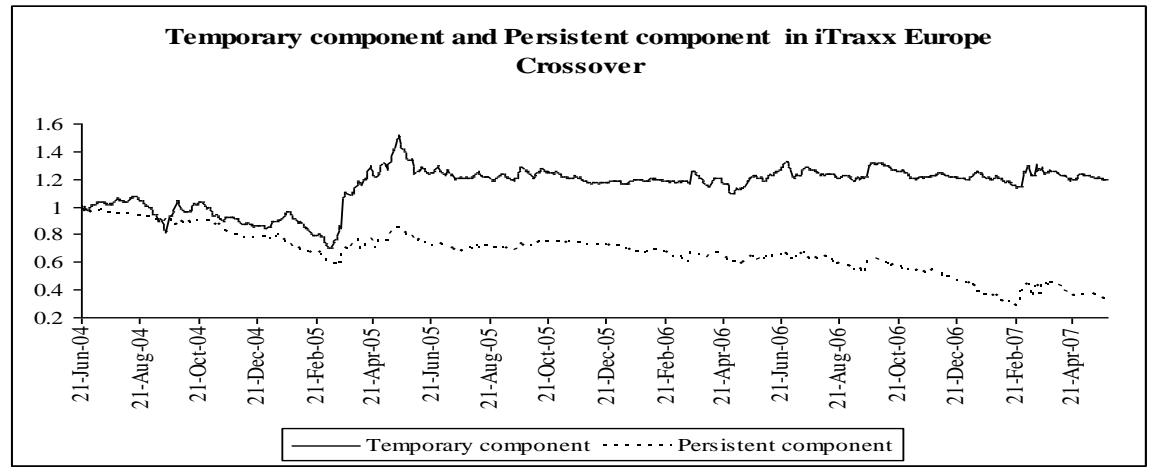

Panel C. Temporary component and persistent component for iTraxx Europe Crossover

Figure 7. Temporary component and persistent component for each of 3 iTraxx Europe indices

\section{References}

Abid, F., \& Naifar, N. (2005). The impact of stock returns volatility on credit default swap rates: a copula study. International Journal of Theoretical \& Applied Finance, 8(8), 1135-1155.

Abid, F., \& Naifar, N. (2006a). Credit-default swap rates and equity volatility: a nonlinear relationship. The Journal of Risk Finance, 7(4), 348-371.

Abid, F., \& Naifar, N. (2006b). The determinants of credit default swap rates: an explanatory study. International Journal of Theoretical and Applied Finance, 9(1), 23-42.

Ait-Sahalia, Y. (1996a). Nonparametric pricing of interest rate derivative securities. Econometrica, 64(3), 527-560.

Ait-Sahalia, Y. (1996b). Testing Continuous-time Models of the Spot Interest Rate. The Review of Financial Studies, 9(2), 385-426.

Avramov, D., Chordia, T., Jostova, G., \& Philipov, A. (2007). Momentum and Credit Rating. The Journal of Finance, 62(5), 2503-2520. 


\section{Macrothink}

International Journal of Accounting and Financial Reporting ISSN 2162-3082 2018, Vol. 8, No. 4

Benkert, C. (2004). Explaining credit default swap premia. The Journal of Futures Markets, 24(1), 71-92.

Brown, R., In, F., \& Fang, V. (2002). Modeling the determinants of swap spreads. The Journal of Fixed Income, 12, 29-40.

Bystrom, H. (2006). Credit Grades and the iTraxx CDS Index Market. Financial Analysts Journal, 62(6), 65-76.

Collin-Dufresne, P., \& Goldstein, R. S. (2001). Do credit spreads reflect stationary leverage ratios?. The Journal of Finance, 56(5), 1929-1957.

Collin-Dufresne, P., Goldstein, R. S., \& Martin, J. S. (2001). The determinants of credit spread changes. The Journal of Finance, 56(6), 2177-2207.

Collin-Dufresne, P., Goldstein, R. S., \& Hugonnier, J. (2004). A general formula for valuing defaultable securities. Econometrica, 72(5), 1377-1407.

Driessen, J. (2005). Is default event risk priced in corporate bonds?. The Review of Financial Studies, 18(1), 165-195.

Duffee, G. R. (1998). The relation between treasury yields and corporate bond yield spreads. The Journal of Finance, 53(6), 2225-2241.

Duffee, G. R., \& Zhou, C. S. (2001). Credit derivatives in banking: Useful tools for managing risk?. Journal of Monetary Economics, 48(1), 25-54.

Duffie, D., \& Singleton, K. J. (1999). Modeling term structures of defaultable bonds. The Review of Financial Studies, 12, 687-720.

Ericsson, J., \& Reneby, J. (2004). An empirical study of structural credit risk models using stock and bond prices. The Journal of Fixed Income, 13(4), 38-49.

Ericsson, J., Jacobs, K., \& Oviedo, R. (2005). The Determinants of Credit Default Swap Premia. Journal of Financial and Quantitative Analysis.

Fama, E. F., \& French, K. R. (1989). Business conditions and expected returns on stocks and bonds. Journal of Financial Economics, 25, 23-49.

Geyer, A. L. J., \& Pichler, S. (1999). A state-space approach to estimate and test multifactor Cox-Ingersoll-Ross models of the term structures. The Journal of Financial Research, 22(1), 107-130.

Gibbons, M. R., \& Ferson, W. (1985). Testing Asset Pricing Models with Changing Expectations and an Unobservable Market Portfolio. Journal of Financial Economics, 14, 217-236.

Gujarati, D. N. (2004). Basic Econometrics (4th ed.). The McGraw-Hill Companies, NY.

Harvey, A. C. (1989). Forecasting, Structural Time Series Models and the Kalman Filter. Princeton University Press, Princeton, NJ. 
Hull, J., \& White, A. (1994). Numerical Procedures of Implementing Term Structure models II: Two-Factor Models. The Journal of Derivatives, 2, 37-47.

Hull, J., Predescu, M., \& White, A. (2004). The relationship between credit default swap spreads, bond yields, and credit rating announcements. Journal of Banking and Finance, 28(11), 2789-2811.

Jarrow, R. A. J., \& Yildiray, Y. (2002). Valuing default swaps under market and credit risk correlation. The Journal of Fixed Income, 11(4), 7-19.

Jong, F., \& Santa-Clara, P. (1999). The dynamics of the forward interest rate curve: A formulation with state variables. Journal of Financial and Quantitative Analysis, 34(1), 131-157.

Longstaff, F. A., \& Schwartz, E. S. (1995a). A simple approach to valuing risky fixed and floating rate debt. The Journal of Finance, 50(3), 789-819.

Longstaff, F A., \& Schwartz, E. S. (1995b). Valuing credit derivatives. The Journal of Fixed Income, 5(1), 6-12

Longstaff, A. F., Mithal, S., \& Neis, E. (2005). Corporate yield spreads: default risk or liquidity? New evidence from the credit default swap market. The Journal of Finance, 60(5), 2213-2253.

Norden, L., \& Weber, M. (2004). Informational efficiency of credit default swap and stock markets: The impact of credit rating announcements. Journal of Banking and Finance, 28(11), 2813-2843.

Schwartz, E., \& Smith, J. E. (2000). Short-term variations and long-term dynamics in commodity prices. Management Science, 46(7), 893-911.

Simon, H. B., \& Nowman, K. B. (1999). Kalman filtering of generalized Vasicek term structure models. Journal of Financial and Quantitative Analysis, 34(1), 115-130.

Skinner, F. S., \& Townend, T. G. (2002). An empirical analysis of credit default swaps. International Review of Financial Analysis, 11(3), 297-309.

Skinner, S., \& Diaz, A. (2003). An empirical study of credit default swaps. The Journal of Fixed Income, 13(1), 28-39.

Stanton, R. (1997). A nonparametric model of term structure dynamics and the market price of interest rate risk. The Journal of Finance, 52(5), 1973-2002.

Wilson, T. C. (1997a). Measuring and managing credit portfolio risk: Part I: Modeling systemic default risk. The Journal of Lending and Credit Risk Management, 79(11), 61-72.

Wilson, T. C. (1997b). Measuring and managing credit portfolio risk: Part II: Portfolio loss distributions. The Journal of Lending and Credit Risk Management, 79(12), 67-78.

Wilson, T. C. (1998). Portfolio credit risk. Economic Policy Review. Federal Reserve Bank of New York, 4(3), 71-82. 
Zhou, C., \& Qing, C. (2000). A state-space model of short and long-horizon stock returns. The Journal of Financial Research, 23(4), 523-544.

\section{Appendix}

Appendix A. Component Names in Series 7 of Markit iTraxx Europe

\begin{tabular}{|c|c|c|c|c|c|c|c|c|c|c|c|}
\hline No. & Ticker & Rating & Va. & No. & Ticker & Rating & Va. & No. & Ticker & $\begin{array}{l}\text { Ratin } \\
\mathrm{g}\end{array}$ & Va. \\
\hline 1 & $\mathrm{AAB}$ & $\mathrm{Aa} 2$ & 3 & 43 & COFP & BBB- & 10 & 85 & VIEFP & A3 & 7 \\
\hline 2 & AEGON & $\mathrm{A} 2$ & 6 & 44 & CPGLN & Baa2 & 9 & 86 & $\mathrm{ADO}$ & Baa2 & 9 \\
\hline 3 & ALZ & Aa3 & 4 & 45 & LUFTHA & Baa3 & 10 & 87 & AKZO & A3 & 7 \\
\hline 4 & ASSGEN & Aa3 & 4 & 46 & DIAG & A3 & 7 & 88 & LORFP & Baa3 & 10 \\
\hline 5 & AVLN & $\mathrm{A} 3$ & 7 & 47 & DSGILN & Baa2 & 9 & 89 & BYIF & A3 & 7 \\
\hline 6 & AXASA & $\mathrm{A} 2$ & 6 & 48 & GUSLN & Baa1 & 8 & 90 & CIBASC & $\mathrm{Baa} 2$ & 9 \\
\hline 7 & MONTE & Aa3 & 4 & 49 & GLHLN & $\mathrm{A} 2$ & 6 & 91 & SGOFP & Baa1 & 8 \\
\hline 8 & BPIIM & $\mathrm{A} 2$ & 6 & 50 & AUCHAN & A & 6 & 92 & EADFP & $\mathrm{A} 1$ & 5 \\
\hline 9 & BBVASM & Aal & 2 & 51 & HENKEL & $\mathrm{A} 2$ & 6 & 93 & GLENCR & Baa3 & 10 \\
\hline 10 & BCPN & Aa3 & 4 & 52 & IMPTOB & Baa3 & 10 & 94 & HANSON & Baa3 & 10 \\
\hline 11 & BESNN & Aa3 & 4 & 53 & KINGFI & Baa3 & 10 & 95 & ICI & $\mathrm{Baa} 2$ & 9 \\
\hline 12 & SANTAN & Aa1 & 2 & 54 & PHG & A3 & 7 & 96 & DSM & $\mathrm{A} 2$ & 6 \\
\hline 13 & BACR & Aa1 & 2 & 55 & MOET & A- & 7 & 97 & LAFCP & Baa2 & 9 \\
\hline 14 & BNP & Aal & 2 & 56 & MKS & Baa2 & 9 & 98 & LINGR & Baa1 & 8 \\
\hline 15 & CAPIM & $\mathrm{A} 1$ & 5 & 57 & METFNL & Baa2 & 9 & 99 & SANFP & $\mathrm{A} 1$ & 5 \\
\hline 16 & CMZB & Aa3 & 4 & 58 & PRTP & BBB- & 10 & 100 & SIEM & Aa3 & 4 \\
\hline 17 & DB & Aal & 2 & 59 & MRWLN & Baa2 & 9 & 101 & SOLBBB & $\mathrm{A} 2$ & 6 \\
\hline
\end{tabular}




\begin{tabular}{|c|c|c|c|c|c|c|c|c|c|c|c|}
\hline 18 & HANRUE & A3 & 7 & 60 & EXHO & $\mathrm{BBB}+$ & 9 & 102 & STORA & Baa3 & 10 \\
\hline 19 & ISPIM & $\mathrm{Aa} 2$ & 3 & 61 & SCACAP & Baa1 & 8 & 103 & TKAGR & Baa2 & 9 \\
\hline 20 & MUNRE & Aa3 & 4 & 62 & TATELN & Baa2 & 9 & 104 & UPMKYM & Baa2 & 9 \\
\hline 21 & RSA & $\mathrm{A} 3$ & 7 & 63 & TSCO & $\mathrm{A} 1$ & 5 & 105 & VINCI & Baa1 & 8 \\
\hline 22 & SCHREI & $\mathrm{Aa} 2$ & 3 & 64 & TMMFP & Baa2 & 9 & 106 & BERTEL & Baa1 & 8 \\
\hline 23 & RBS & Aaa & 1 & 65 & ULVR & A1 & 5 & 107 & BRITEL & Baa1 & 8 \\
\hline 24 & CRDIT & $\mathrm{Aa} 2$ & 3 & 66 & CENTRI & $\mathrm{A} 3$ & 7 & 108 & DT & A3 & 7 \\
\hline 25 & ZURNVX & $\mathrm{A} 1$ & 5 & 67 & EOAGR & $\mathrm{A} 2$ & 6 & 109 & FRTEL & A3 & 7 \\
\hline 26 & VLVY & $\mathrm{A} 3$ & 7 & 68 & EDNIM & Baa2 & 9 & 110 & OTE & Baa1 & 8 \\
\hline 27 & BMW & $\mathrm{A} 1$ & 5 & 69 & EDF & Aa1 & 2 & 111 & KPN & $\mathrm{Baa} 2$ & 9 \\
\hline 28 & $\mathrm{MICH}$ & Baa2 & 9 & 70 & ELESM & $\mathrm{A} 3$ & 7 & 112 & PSON & Baa1 & 8 \\
\hline 29 & CONTI & Baa1 & 8 & 71 & ENEL & $\mathrm{A} 1$ & 5 & 113 & PUBFP & Baa2 & 9 \\
\hline 30 & DCX & Baal & 8 & 72 & ELEPOR & $\mathrm{A} 2$ & 6 & 114 & REEDLN & Baa1 & 8 \\
\hline 31 & GKNLN & Baa3 & 10 & 73 & ENBW & A2 & 6 & 115 & RTRGRP & Baa1 & 8 \\
\hline 32 & PEUGOT & Baa1 & 8 & 74 & FRTUM & $\mathrm{A} 2$ & 6 & 116 & STM & A3 & 7 \\
\hline 33 & RENAUL & Baa1 & 8 & 75 & GASSM & $\mathrm{A} 1$ & 5 & 117 & TITIM & $\mathrm{Baa} 2$ & 9 \\
\hline 34 & VLOF & Baa2 & 9 & 76 & GAZDF & Aa1 & 2 & 118 & TELEFO & Baa1 & 8 \\
\hline 35 & VW & $\mathrm{A} 3$ & 7 & 77 & IBERDU & $\mathrm{A} 2$ & 6 & 119 & TKA & A3 & 7 \\
\hline 36 & ACCOR & BBB & 9 & 78 & NGGLN & Baa1 & 8 & 120 & TELNOR & A2 & 6 \\
\hline 37 & ELTLX & Baa2 & 9 & 79 & REPSM & Baa1 & 8 & 121 & TLIASS & $\mathrm{A} 2$ & 6 \\
\hline 38 & ABLN & Baa2 & 9 & 80 & RWE & A1 & 5 & 122 & VIVFP & Baa2 & 9 \\
\hline 39 & ALTSM & Baa2 & 9 & 81 & LYOE & $\mathrm{A} 2$ & 6 & 123 & VOD & Baa1 & 8 \\
\hline 40 & BATSLN & Baa1 & 8 & 82 & UNFSM & Baa1 & 8 & 124 & WOLKLU & Baa1 & 8 \\
\hline
\end{tabular}




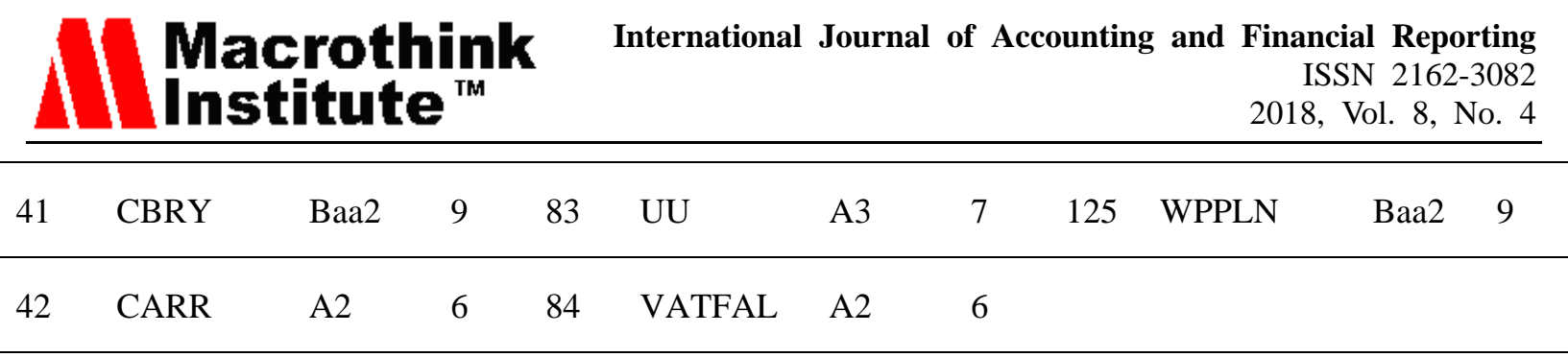

Average Rating A2/A3 6.896

Note: This table reports the credit rating and rating numerical value for 125 component names in series 7 of Markit iTraxx Europe. The average rating is affine from the average component rating numerical value.

Appendix B. Component names in series 7 of Markit iTraxx Europe Crossover

\begin{tabular}{|c|c|c|c|c|c|c|c|}
\hline No. & Ticker & Rating & Numerical value & No. & Ticker & Rating & Numerical value \\
\hline 1 & ALUFP & $\mathrm{Ba} 2$ & 12 & 26 & KABEL & $\mathrm{Ba} 3$ & 13 \\
\hline 2 & NELL & $\mathrm{Ba} 3$ & 13 & 27 & AHOLD & Baa3 & 10 \\
\hline 3 & BCMAU & B1 & 14 & 28 & LADLN & $\mathrm{Ba} 2$ & 12 \\
\hline 4 & $\mathrm{BAB}$ & Baa3 & 10 & 29 & MESSA & B3 & 16 \\
\hline 5 & CWLN & B1 & 14 & 30 & TDCDC & $\mathrm{Ba} 3$ & 13 \\
\hline 6 & CAPP & $\mathrm{BB}+$ & 11 & 31 & NSINO & Ba1 & 11 \\
\hline 7 & CODERE & $\mathrm{B} 2$ & 15 & 32 & NXPBV & B1 & 14 \\
\hline 8 & COGNIS & $\mathrm{B} 2$ & 15 & 33 & ONOFIN & B3 & 15 \\
\hline 9 & COLTLN & $\mathrm{B} 2$ & 15 & 34 & PORTEL & $\mathrm{Baa} 2$ & 9 \\
\hline 10 & CORUS & Ba1 & 11 & 35 & PROSIE & $\mathrm{Ba} 1$ & 11 \\
\hline 11 & DEGUSS & Baa3 & 10 & 36 & RALFP & Ba1 & 11 \\
\hline 12 & EMI & B1 & 14 & 37 & RAYAC & Ba1 & 11 \\
\hline 13 & FIAT & Ba1 & 11 & 38 & RHA & $\mathrm{Ba} 3$ & 13 \\
\hline 14 & FKI & $\mathrm{Ba} 2$ & 12 & 39 & SAS & B1 & 14 \\
\hline 15 & FREGR & $\mathrm{Ba} 2$ & 12 & 40 & SEAT & $\mathrm{Ba} 3$ & 13 \\
\hline 16 & $\mathrm{SDC}$ & B2 & 16 & 41 & MDPAC & $\mathrm{B} 2$ & 16 \\
\hline 17 & GFCFP & Baa3 & 10 & 42 & SOLSM & Baa3 & 10 \\
\hline
\end{tabular}




\begin{tabular}{|c|c|c|c|c|c|c|c|c|}
\hline & We & & & International & I Journa & al of Accou & ting and & $\begin{array}{r}\text { Financial Reporting } \\
\text { ISSN 2162-3082 } \\
\text { 2018, Vol. 8, No. } 4\end{array}$ \\
\hline 18 & GROHE & B2 & 16 & & 43 & VNU & B2 & 16 \\
\hline 19 & HAVAS & $\mathrm{Ba} 2$ & 12 & & 44 & RNK & $\mathrm{Ba} 3$ & 13 \\
\hline 20 & HELLAS & B2 & 16 & & 45 & TUIGR & B1 & 14 \\
\hline 21 & INEGRP & B1 & 14 & & 46 & IESYRP & B3 & 15 \\
\hline 22 & IFX & B1 & 14 & & 47 & UPC & B1 & 14 \\
\hline 23 & IPRLN & Ba3 & 13 & & 48 & VMED & B2 & 16 \\
\hline 24 & ISYSLN & $\mathrm{Ba} 3$ & 13 & & 49 & WDAC & B2 & 16 \\
\hline 25 & ITVLN & Baa3 & 10 & & 50 & $\begin{array}{l}\text { WINDI } \\
\mathrm{M}\end{array}$ & B2 & 16 \\
\hline
\end{tabular}

Average Rating $\quad$ Ba3/B1 13.1

Appendix C. Component names in series 7 of Markit iTraxx Europe Hivol

\begin{tabular}{llll}
\hline No. & Ticker & Rating & Numerical value \\
\hline 1 & ACCOR & BBB & 9 \\
\hline 2 & ELTLX & Baa2 & 9 \\
\hline 4 & BRITEL & Baa1 & 8 \\
\hline 5 & CBRY & Baa2 & 9 \\
\hline 6 & COFP & BBB- & 10 \\
\hline 7 & CIBASC & Baa2 & 9 \\
\hline 8 & CPGLN & Baa2 & 9 \\
\hline 9 & CONTI & Baa1 & 8 \\
\hline 10 & DCX & Baa1 & 8 \\
\hline 11 & LUFTHA & Baa3 & 10 \\
\hline 12 & DSGILN & Baa2 & 9 \\
\hline 13 & GUSLN & Baa1 & 8 \\
\hline
\end{tabular}




\begin{tabular}{llll}
\hline 14 & GLENCR & Baa3 & 10 \\
\hline 15 & HANSON & Baa3 & 10 \\
\hline 16 & ICI & Baa2 & 9 \\
\hline 17 & KINGFI & Baa3 & 10 \\
\hline 19 & KPN & A2 & 6 \\
\hline 20 & MKS & Baa2 & 9 \\
\hline 21 & PSON & Baa1 & 8 \\
\hline 22 & PRTP & BBB- & 10 \\
\hline 24 & MRWLN & Baa2 & 9 \\
\hline 25 & STORA & Baa3 & 10 \\
\hline 26 & TATELN & Baa2 & 9 \\
\hline 27 & TITIM & Baa2 & 9 \\
\hline 28 & TMMFP & Baa2 & 9 \\
\hline 29 & UPMKYM & Baa2 & 9 \\
\hline 30 & VLOF & Baa2 & 9 \\
\hline Average Rating & & Baa2 & 9 \\
\hline
\end{tabular}

\section{Copyright Disclaimer}

Copyright for this article is retained by the author(s), with first publication rights granted to the journal.

This is an open-access article distributed under the terms and conditions of the Creative Commons Attribution license (http://creativecommons.org/licenses/by/4.0/) 